\title{
A FOME DO CAPITAL E A EXPROPRIAÇÃO DOS BENS COMUNS - LAND/GREEN GRABBING E SUAS RELAÇÕES COM A REPRODUCCÃO DO DISCURSO NEOLIBERAL POR TRÁS DO FENÔMENO DAS MUDANÇAS CLIMÁTICAS
}

\author{
Alexandre Sabino do Nascimento \\ Universidade Federal da Paraíba, Departamento de Geociências, João Pessoa, PB, Brasil \\ alexandre.sabino@academico.ufpb.br
}

\begin{abstract}
RESUMO
Observou-se que temas como os da segurança alimentar, mudanças climáticas, produção de alimentos e biocombustíveis e, por extensão, governança das terras passam a fazer parte da agenda neoliberal de organismos da gestão política mundial e do capital financeiro. Esses temas fazem parte de um processo de acumulação primitiva permanente, viabilizada por meio de práticas neocoloniais e neoextrativistas, que contrariam ideias como a soberania alimentar, autonomia dos povos e o direito aos bens comuns. Esse artigo tem por objetivo identificar e sistematizar uma possível chave de leitura em torno da análise da relação entre conceitos, agendas e paradigmas, aparentemente, desconexos como: mudanças climáticas, neoliberalismo/neoliberalização, segurança/soberania alimentar, land grabbing, green grabbing, assetização, desenvolvimento sustentável, conservação ambiental, Economia Verde e Bioeconomia, entre outros. Como metodologia para se chegar aos resultados alcançados efetivou-se uma pesquisa exploratória, bibliográfica e documental. Conclui-se que, atualmente, evolui uma corrida global por terras e recursos naturais, que representa certo rentismo ecológico manifestado nas análises dos fenômenos de land grabbing e green grabbing, esses fenômenos, por sua vez, estão associados a práticas e dispositivos neoliberalizantes e financeiros presentes na construção de uma agenda global construída sobre o discurso apocalíptico de uma sociedade de risco global ligada a paradigma das mudanças climáticas.
\end{abstract}

Palavras-chave: Mudanças Climáticas. Land/Green Grabbing. Bens Comuns. Financeirização. Neoliberalização.

\section{THE CAPITAL HUNGER AND EXPROPRIATION OF COMMON - LAND I GREEN GRABBING AND THEIR RELATIONSHIPS WITH THE REPRODUCTION OF NEOLIBERAL DISCOURSE BEHIND THE PHENOMENON OF CLIMATE CHANGE}

\begin{abstract}
It was observed that topics such as food security, climate change, food production and biofuels and, by extension, land governance become part of the neoliberal agenda of bodies of world political management and financial capital. These themes are part of a process of permanent primitive accumulation, made possible through neo-colonial and neo-extractive practices, which contradict ideas such as food sovereignty, autonomy of peoples and the right to common goods. This article aims to identify and systematize a possible key for reading around the analysis of the relationship between concepts, agendas and paradigms, apparently disconnected, such as: climate change, neoliberalism / neoliberalization, food security / sovereignty, land grabbing, green grabbing, assetization , sustainable development, environmental conservation, Green Economy and Bioeconomy, among others. As a methodology to reach the results achieved, exploratory, bibliographic and documentary research was carried out. It is concluded that, currently, a global race for lands and natural resources evolves, which represents a certain ecological rentism manifested in the analysis of the phenomena of land grabbing and green grabbing, these phenomena, in turn, are associated with neoliberalizing and financial practices and devices. present in the construction of a global agenda built on the apocalyptic discourse of a global risk society linked to the climate change paradigm.
\end{abstract}

Keywords: Climate changes. Land / Green Grabbing. Commons. Financialization. Neoliberalization. 


\section{INTRODUÇÃO}

Para Borras Jr \& Sauer (2016) temas como os da segurança alimentar, mudanças climáticas, produção de alimentos e biocombustíveis e, por extensão, governança das terras passam a fazer parte da agenda neoliberal de organismos da gestão política mundial e do capital financeiro. Esses temas fazem parte de um processo de acumulação primitiva permanente (BRANDÃO, 2010), viabilizada por meio de práticas neocoloniais e neoextrativistas (SVAMPA, 2019), que contrariam ideias como a soberania alimentar, autonomia dos povos e o direito aos bens comuns. Assim, acredita-se, nesse estudo, que o atual quadro de mundialização e financeirização do capital (CHESNAIS, 1996) tem levado a reestruturações territoriais dentro do processo de acumulação do capital, este tem se baseado, principalmente, no seguinte tripé: financeirização da economia, reestruturação produtiva e globalização do ideário neoliberal.

Esse artigo tem por objetivo identificar e sistematizar uma possível chave de leitura em torno da análise da relação entre conceitos, agendas e paradigmas, aparentemente, desconexos como: mudanças climáticas, neoliberalismo/neoliberalização, segurança/soberania alimentar, land grabbing (apropriação de terras), green grabbing (apropriação verde), "assetização das terras", desenvolvimento sustentável, conservação ambiental, Economia Verde e Bioeconomia, entre outros. Como metodologia para se chegar aos resultados alcançados fez-se uso de pesquisa exploratória, bibliográfica e documental, que buscou em literatura especializada nacional e internacional e documentos de organizações multilaterais os dados e informações utilizados na argumentação presente nesse artigo.

Para enfrentar os "desafios" da crise estrutural do capital (MESZÁROS, 2011) países centrais passam a utilizar uma série de dispositivos (AGAMBEN, 2005) ${ }^{1}$ como soluções ilusórias - boas práticas, ligadas a um discurso de um possível desenvolvimento sustentável, ou a conceitos como os de sustentabilidade, resiliência, pagamentos por serviços ambientais/ecossistêmicos, governança (corporativa) urbana, de terras, ambiental etc., segurança alimentar, mercado de títulos verdes entre outros. Muito desses dispositivos podem ser encontrados na Agenda 2030 da ONU para o Desenvolvimento Sustentável e seus 17 Objetivos de Desenvolvimento Sustentável - ODS ${ }^{2}$ e no Acordo de Paris 3 .

Tal produção desses dispositivos liga-se à busca e necessidade de criação de certos consensos e de uma agenda global quanto a problemática socioambiental derivada das mudanças climáticas e de suas soluções via mercado, que se dão via a despossessão/espoliação de bens comuns, principalmente, dos povos do Sul Global. Essas agendas trazem (re)regulações associadas ao processo de neoliberalização (BRENNER; PECK; THEODORE, 2012), que atuam no sentido de ampliar ou consolidar formas mercantilizadas e commodificadas de vida social. As mesmas podem ser verificadas, segundo nossa análise, nas novas legislações ligadas às questões ambiental e agrária brasileira.

Em nossa leitura associa-se a isso as ideias de land grabbing/acaparamiento de tierras ${ }^{4}$ (HARVEY, 2014, SASSEN, 2016; BORRAS Jr.; SAUER, 2016; PEREIRA, 2017; SEUFERT; MENDONÇA; PITTA, 2018; FERNANDES; FREDERICO; PEREIRA, 2019; FREDERICO; ALMEIDA, 2019), assim como a apropriação de terras e recursos para fins de conservação ambiental via a criação de dispositivos/instrumentos de mitigação e compensação ambientais, que estão promovendo a apropriação de terras e de recursos para supostos propósitos ambientais que resultam no chamado fenômeno da "green grabbing" ou "grilagem verde". Dar-se assim a apropriação ou expropriação verde ligada à crescente commodificação ou mercantilização da natureza em nome da propalada sustentabilidade, que por sua vez está associada a tentativa de fomento de uma "Economia verde" (DEMPSEY; ROBERTSON, 2012; FAIRHEAD; LEACH; SCOONES, 2012; FLETCHER, DRESSLER, BÜSCHER, 2014; PACKER, 2015; FURTADO, 2015; BORRAS Jr. \& SAUER, 2016; DEMPSEY, 2016).

Correlato a essas ações tem-se a transformação da terra em ativo financeiro via o processo, chamado por Birch (2016), Ward \& Swyngedouw (2018); Aalbers (2017), de "assetização", que pode se realizar sobre

\footnotetext{
${ }_{1}^{1}$ Agamben (2005), valendo-se da discussão de Foucault sobre "governamentalidade" como objeto de estudo das formas de governar, utiliza o termo "dispositivo" com referência a um conjunto constituído por instituições, procedimentos, análises, reflexões, cálculos, métricas, táticas, estratégias que permitem exercer formas de exercício do poder, tendo por objetivo principal regular a população e o território.

2 Disponível em: https://www.un.org/sustainabledevelopment/es/objetivos-de-desarrollo-sostenible/. Acesso: 20 jul. 2020.

3 O Acordo de Paris foi firmado na COP-21. Este representa um consenso entre os países-membros da ONU em torno da mitigação dos efeitos da mudança do clima.

${ }^{4}$ Ligado ao conceito de land grabbing assinala-se com Harvey (2014) a fundação e consolidação de uma classe de rentistas (e proprietária), potencialmente poderosa, que regula o acesso a reserva de valores de uso em virtude do seu poder monopolista de classe e das rendas que ela extrai da terra.
} 
bens comuns (espaciais), ativos materiais, a exemplo da terra. Para esses autores a "assetização" seria a transformação de bens comuns em recursos que geram renda sem sua venda. Fato que se liga a formação de capital fictício, já que o valor de um ativo não é determinado primariamente por sua venda (como acontece com as commodities), mas por suas atribuídas fontes futuras de renda.

Inicialmente, trataremos da produção de dispositivos e consensos e narrativas ligadas a racionalidade neoliberal, para em seguida apresentar alguns dos dispositivos neoliberais - best practices - ligados ao paradigma das mudanças climáticas e da financeirização criados recentemente, para logo após se discutir a imbricação de mercado global e formação de monopólios e sua coevolução com o processo de mercantilização da natureza. Em seguida apresenta-se os conceitos de green grabbing e land grabbing. $\mathrm{E}$ finaliza-se com a relação entre esses dispositivos ou tecnologias de poder com a emergência de um período de pós-política e negação de direitos e dos comuns. Para tanto se utilizará de arcabouço teórico inter(trans)disciplinar que envolve autores da Geografia, Economia, Ciências Sociais etc.

\section{A RACIONALIDADE NEOLIBERAL E A IMPOSIÇÃO DE DISPOSITIVOS/BOAS PRÁTICAS LIGADAS AO DISCURSO DO DESENVOLVIMENTO SUSTENTÁVEL}

O capitalismo vem passando por rodadas de neoliberalização (BRANDÃO, 2017) que conformam um processo dinâmico de reestruturação produtiva e de transformação da organização e intervenção do Estado no espaço, ou como assevera Brenner (2010) representam novos projetos e estratégias estatais. Esse processo para Brenner, Peck e Theodore (2012) teria três dimensões principais: 1) experimentação regulatória; 2) transferência interjurisdicional de políticas; 3) formação de regimes de normas transnacionais (agendas globais).

Assim, dar-se o processo de reescalonamento que flexibiliza e rearticula os padrões e políticas institucionais de escala nacional para introduzir novas formas de governo supranacional (governança global), e, simultaneamente, esse reescalonamento atravessa os níveis local e regional com toda sorte de prerrogativas regulatórias e dispositivos, que incentivam o surgimento de novas formas de governança ligadas a produção de um clima favorável a (re)localização de capitais, infraestruturas e recursos humanos, promovendo assim um processo de reestruturação territorial, apropriação e expropriação de recursos territoriais (BRANDÃO, 2010), e em paralelo promove a destruição criativa da terra (HARVEY, 2011).

A formação de agendas globais neoliberais está ligada a produção de consensos que faz parte da racionalidade neoliberal do capitalismo contemporâneo, que para Dardot \& Laval (2016) tende a estruturar e organizar tanto a ação dos governantes, como a conduta dos governados, através de discursos, práticas e dispositivos (AGAMBEN, 2005) que determinam um novo modo de governo (governamentabilidade) dos homens ${ }^{5}$. A análise da produção de consensos é necessária para entendermos como é possível Estados nacionais, com governos de diferentes matizes políticos, incorporarem discursos e políticas danosas às suas economias e povos, e enveredarem para políticas de cunho neoliberais ligadas há um capitalismo de dominância financeira (CHESNAIS, 2005).

Um dos argumentos/paradigmas ou ideia-chave ligada a estrutura flexível de unificação de interesses políticos nas mais diferentes espacialidades e temporalidades foi o paradigma do desenvolvimento. Esse serviu de farol para os mais diferentes lugares, levando-os a seguir caminhos que os conduziram da euforia ao desencanto. Ou como assevera W. Sachs apud Acosta (2017, p. 42) "O engano e a desilusão, os fracassos e os crimes têm sido companheiros permanentes do desenvolvimento. Contam uma mesma história: não funcionou. Além disso, desapareceram as condições históricas que possibilitaram a proeminência dessa ideia: o desenvolvimento tornou-se antiquado".

Sublinha-se também o papel histórico dos economistas ligados a esse paradigma. Santos (2007) aponta que para propiciar segurança, confiança e estímulo ao investimento privado via o uso do Tesouro Público, foram necessários argumentos de peso que justificassem a transferência da poupança dos mais pobres para o bolso dos mais ricos, e que a linguagem científica de ciências como a Economia Política foi bem eficaz para tanto. Santos (2007) também aponta para a difusão do planejamento capitalista e sua ligação com o paradigma do desenvolvimento.

Acosta (2017) destaca que a metáfora do desenvolvimento foi usada habilmente pelos países hegemônicos, com destaque para os Estados Unidos da América, para firmar as bases conceituais de

5 Michel Foucault - Sociedade, Território, População (2008). 
outra forma de imperialismo: "o desenvolvimento". Esse paradigma/dispositivo quando passa a apresentar suas falhas e limitações tenta se modernizar adotando sobrenomes como o tão propalado, atualmente, "desenvolvimento sustentável", como aponta Acosta

\begin{abstract}
Quando os problemas começaram a minar nossa fé no "desenvolvimento" e a grande teoria do desenvolvimento fez água por todos os lados, buscamos alternativas de desenvolvimento. Como aponta o sociólogo peruano Aníbal Quijano, colocamos sobrenomes ao desenvolvimento para diferenciá-lo do que nos incomodava, mas seguimos pela trilha do desenvolvimento: desenvolvimento econômico, desenvolvimento social, desenvolvimento local, desenvolvimento global, desenvolvimento rural, desenvolvimento sustentável ou sustentado, ecodesenvolvimento, etnodesenvolvimento, desenvolvimento humano, desenvolvimento endógeno, desenvolvimento com igualdade de gênero, codesenvolvimento, desenvolvimento transformador... desenvolvimento, no final das contas. (ACOSTA, 2017, p. 48-49).
\end{abstract}

Como já foi dito as condições históricas que possibilitaram a proeminência do/da discurso/ideologia de desenvolvimento se perderam, e, atualmente, o sistema capitalista passa por um período de crise estrutural (MÉSZÁROS, 2011) ${ }^{6}$, que se deflagra em crises constantes e cada vez maiores. Nesse quadro, países periféricos - que na maioria das vezes operam com suas economias na forma emergencial de modo permanente (PAULANI, 2008) passam a conviver, há algumas décadas, com uma espécie de ajuste fiscal permanente, que por sua vez faz parte de um processo de acumulação primitiva permanente (BRANDÃO, 2010). Tudo isso nos revela como o capitalismo representa para a maioria dos habitantes do planeta, não uma promessa ou sonho: mas sim um pesadelo realizado (ACOSTA, 2017).

$\mathrm{Na}$ América Latina tem se moldado um padrão latino americano de integração econômica e desenvolvimento capitalista em um contexto de convergência de múltiplas crises. Isso leva a produção de um espaço com alto padrão de desigualdades, e há um processo de crescente destruição criativa da natureza (HARVEY, 2011) carregado de injustiças sociais e ambientais (ACSERALD, CAMPELO, BEZERRA, 2009).

No início do século XXI há a emergência do discurso neoliberal, que vem na fissura aberta pelo fracasso do paradigma do desenvolvimento. Para Acosta isso se deu da seguinte forma:

A confiança no desenvolvimento - enquanto processo planificado para superar o atraso - fissurou-se nas décadas de 1980 e 1990. Isso ajudou a abrir as portas às reformas de mercado de inspiração neoliberal, em que a busca pelo desenvolvimento devia dar lugar às pretensamente todo-poderosas forças do mercado. Sem a "perniciosa" ingerência do Estado, o desenvolvimento surgiria espontaneamente. O neoliberalismo, porém, não superou a teoria do progresso em suas raízes coloniais. Pelo contrário, reproduziu e reproduz uma visão rejuvenescida das velhas perspectivas hegemônicas do Norte global. (ACOSTA, 2017, p. 63)

\title{
Sobre o processo de neoliberalização e sua relação com a avanço da desigualdade Stiglitz escreve
}

A desigualdade tem sido uma escolha. No início da década de 1970, uma onda deliberada de mudanças ideológicas, institucionais e legais começou a reconfigurar o mercado. Na vanguarda desta onda estava a desregulação, que, de acordo com os seus defensores, aliviaria os constrangimentos sobre a economia, libertando-a para prosperar. A par dela estavam as taxas de impostos muito mais reduzidas sobre os rendimentos de topo, com o objetivo de fazer o dinheiro fluir para as poupanças e investimentos privados, e não para o Estado. Em terceiro lugar, estavam os cortes na despesa com os apoios sociais, para incentivar as pessoas a trabalhar. O argumento era o de que, com o Estado fora do caminho, a criatividade do mercado - e o engenho do sector financeiro -

6 Para Mészáros "Expansionista, destrutivo e, no limite, incontrolável, o capital assume cada vez mais a forma de uma crise endêmica, como um depressed continuum, como uma crise cumulativa, crônica e permanente, com a perspectiva de uma "crise estrutural cada vez mais profunda", ao contrário da sua conformação anterior, cíclica, que alternava fases de desenvolvimento produtivo com momentos de "tempestade". (MESZAROS, 2011, p. 18).

${ }^{7}$ Harvey, também, explica a ascensão do neoliberalismo: "Minha opinião é que se refere a um projeto de classe que surgiu na crise dos anos 1970. Mascarada por muita retórica sobre liberdade individual, autonomia, responsabilidade pessoal e as virtudes da privatização, livre-mercado e livre-comércio, legitimou políticas draconianas destinadas a restaurar e consolidar o poder da classe capitalista. Esse projeto tem sido bem-sucedido, a julgar pela incrível centralização da riqueza e do poder observável em todos os países que tomaram o caminho neoliberal. E não há nenhuma evidência de que ele está morto. Um dos princípios básicos pragmáticos que surgiram na década de 1980, por exemplo, foi o de que o poder do Estado deve proteger as instituições financeiras a todo custo" (HARVEY, 2011, p. 16). 
revitalizaria a sociedade. [...] Hoje em dia, podemos olhar para trás e conferir o saldo destas "reformas": a pior crise económica em 80 anos, um crescimento mais lento do que nos 30 anos anteriores e um aumento descontrolado da desigualdade. Sabemos também que a "desregulação" é, na verdade "re-regulação" - isto é, um novo conjunto de regras para o funcionamento da economia que favorece um grupo específico de intervenientes. (STIGLITZ, 2017, p. 47-48).

O que impressiona é que essas mudanças ideológicas, institucionais e legais, os tais novos arranjos político-econômico e institucionais, não combateram como o prometido as desigualdades e os principais efeitos negativos do sistema como a pobreza, fome, e degradação ambiental, mas pelo contrário exacerbaram as desigualdades e seus efeitos. Destaca-se que esse grupo específico de intervenientes que Stiglitz aponta são agentes ligados ao capital fictício ou portador de juros. Sobre a relação do neoliberalismo com os mesmos Harvey (2020) escreve "Esse modelo neoliberal repousa cada vez mais no capital fictício e em uma vasta expansão na oferta de moeda e na criação de dívida. Já está enfrentando o problema da demanda efetiva insuficiente para realizar os valores que o capital é capaz de produzir"8

Para enfrentar o avanço da desigualdade e as "crises socioambientais" países passam a utilizar uma série de dispositivos (AGAMBEN, 2005) neoliberais como soluções ilusórias - boas práticas, ligadas a um discurso de um possível desenvolvimento sustentável, ou a conceitos como os de sustentabilidade, uso sustentável da terra ${ }^{9}$, resiliência, serviços ambientais/ecossistêmicos ${ }^{10}$, custo social do carbono ${ }^{11}$, governança corporativa ${ }^{12}$ (urbana, terras, ambiental etc.), segurança alimentar e energética (energias renováveis) ${ }^{13}$, "Environment and Natural Resource Security"14 (Segurança dos recursos ambientais e

8 Disponível em: http://www.esquerdadiario.com.br/Politicas-anticapitalistas-em-tempos-de-COVID-19. Acesso: 30 mar. 2020. 9 Sobre o uso/governança sustentável da terra podemos encontrar "recomendações" de "boas práticas" nas ações de think thanks como e Institute for European Environmental Policy (IEEP) com a promoção da reestruturação da Política Agrícola Comum (PAC) que influencia a gestão da terra na Europa, com suas diretrizes em documentos como "Getting to the roots of sustainable land management" Disponível em: https://ieep.eu/uploads/articles/attachments/5555ad71-11e5-4b33-958879179489ebde/Getting\%20to\%20the\%20roots\%20of\%20sustainable\%20land\%20management\%20(IEEP,\%20December\%202 019).pdf?v=63742700166. Acesso: 03 mar. 2020. Ou nos documentos e textos de organismos multilaterais como a Food and Agriculture Organization (FAO) ou da própria ONU, como o estudo "Sustainable land use for the 21st century". Disponível em: https://sustainabledevelopment.un.org/content/documents/1124landuse.pdf. Acesso: 04 mar. 2020.

10 A FAO um dos organismos especializados das Nações Unidas afirma que os serviços ecossistêmicos "[...] hacen posible la vida humana, por ejemplo, al proporcionar alimentos nutritivos y agua limpia; al regular las enfermedades y el clima; al apoyar la polinización de los cultivos y la formación de suelos, y al ofrecer beneficios recreativos, culturales y espirituales. Si bien se estima que estos bienes tienen un valor de 125 billones de USD, no reciben la atención adecuada en las políticas y las normativas económicas, lo que significa que no se invierte lo suficiente en su protección y ordenación". Disponível em: http://www.fao.org/ecosystem-services-biodiversity/es/. Acesso: 15 jul. 2020.

11 O custo social do carbono (SCC) é uma estimativa, em dólares, dos danos econômicos que resultariam da emissão de uma tonelada adicional de gases de efeito estufa na atmosfera. O SCC coloca os efeitos das mudanças climáticas em termos econômicos para ajudar os formuladores de políticas e outros tomadores de decisão a entender os impactos econômicos das decisões que aumentariam ou diminuiriam as emissões. Atualmente, o SCC é usado pelos governos local, estadual e federal para informar bilhões de dólares em decisões de políticas e investimentos nos Estados Unidos e no exterior. Destaca-se que a criação de tais métricas serve como base para o processo de assetização das terras e natureza apontado nesse estudo. Para mais informações ver "Social Cost of Carbon 101 - A review of the social cost of carbon, from a basic definition to the history of its use in policy analysis". Disponível em: https://media.rff.org/documents/SCC_Explainer.pdf. Acesso: 15 jul. 2020. Ou nos documentos da United States Environmental Protection Agency "The Social Cost of Carbon - Estimating the Benefits of Reducing Greenhouse Gas Emissions". Disponível em: https://19january2017snapshot.epa.gov/climatechange/social-costcarbon_html. Acesso: 16 jul. 2020. Ou no editorial da revista Nature "Base the social cost of carbon on the Science - The potential economic damage from global warming should not be influenced by politics". Disponivel em: https://www.nature.com/news/base-the-social-cost-of-carbon-on-the-science-1.21312. Acesso: 16 jul. 2020.

12 Entendendo a Governança Corporativa como uma inovação financeira Grün (2005, p. 71) aponta o papel das organizações multilaterais na sua difusão "Talvez não seja exagero dizer que a governança corporativa é uma espécie de coroamento do conjunto das principais soluções mágicas que advém dos conselhos dos órgãos financeiros internacionais para fomentar o desenvolvimento econômico - e, como veremos a seguir, também social - dos países menos desenvolvidos. Seus arautos serão indivíduos escolhidos entre os membros mais internacionalizados das profissões, chegando a rotular a governança corporativa como uma necessidade do mundo moderno e assim estigmatizando seus possíveis adversários como atrasados". 13 Segundo o World Business Council for Sustainable Development (Conselho Empresarial Mundial para o Desenvolvimento Sustentável - WBCSD) "Os custos das tecnologias renováveis diminuíram para níveis competitivos, enquanto novos avanços tecnológicos e de mercado estão ajudando a superar padrões de geração variáveis. Isso torna as renováveis uma oportunidade de investimento lucrativo. À medida que a demanda global de eletricidade cresce, a construção e a operação de projetos renováveis são um modelo de negócios rentável e sustentável para investidores, desenvolvedores, empresas de serviços públicos e consumidores". Disponível em: https://www.wbcsd.org/Programs/Climate-and-Energy/Energy/REscale. Acesso: 25 jul. 2020.

14 De acordo com o estudo da OCDE "Better Policies for Development - Recommendations for Policy Coherence" no bojo da "Environment and Natural Resource Security" estão incluídas: Food Security; Water Security e Energy Security. Disponível em: https://read.oecd-ilibrary.org/development/better-policies-for-development_9789264115958-en\#page6. Acesso: 25 jul. 2020. Algo nesse sentido pode ser visto também nos trabalhos de outro grande organismo multilateral como a Agência dos Estados Unidos para 
naturais) entre outros, defendidos como única via, e que possuem um potencial integrador e consensual dentro de uma "Global Governance" como a pretendida pela ONU com os ODS.

Fato que se liga a criação do consenso quanto a determinada problemática socioambiental construída de modo a conter já os meios de sua solução, que em nossa análise, tratam-se de meios mercadológicos/financeiros ligados a mercantilização/privatização dos bens comuns e "precificação" da natureza, sem falar nas soluções ligadas a dita "Economia Verde" e as soluções tecnológicas ligadas a "Indústria 4.0" e a "Bioeconomia"15. (ETC GROUP, 2020; PARCKER, 2015; BIRCH, 2016; DEMPSEY, 2016).

Pode-se ver esse discurso na fala de Niky Fabiancic, coordenador da ONU no Brasil, no evento "SDG Investment Forum" (Fórum Global de Investimento em Desenvolvimento Sustentável), realizado em São Paulo para discutir analisar oportunidades e desafios sobre os investimentos necessários à execução dos Objetivos de Desenvolvimento Sustentável - ODS. ${ }^{16}$ Segundo seus organizadores a principal mensagem do Fórum foi o reconhecimento de que os ODS representam uma oportunidade financeira para as empresas. Fabiancic afirmou "O know how empresarial é muito valioso e determinante para dar escala a boas práticas que viabilizem a economia sustentável"17. Com mais de 140 representantes do mundo corporativo, setor público, sociedade civil e academia, o SDG Investment Forum — o primeiro realizado no mundo - enfatizou que a agenda da ONU é uma oportunidade para os negócios.

Como podemos observar o grande negócio verde cresce com apoio de organizações multilaterais como a ONU. Observou-se, pelos relatos, que durante o encontro, promovido pelo Pacto Global da ONU, lideranças empresariais discutiram os desafios de alinhar os interesses do setor privado aos ODS, tais como criar um mercado de títulos ODS, entre outros, fator ligado ao processo de securitização bastante comum na atual economia com dominância das finanças (CHESNAIS, 2005). Sullivan (2012) analisa como o processo de crescente financeirização da vida cotidiana se estende para os discursos de conservação ambiental e sustentabilidade, que por sua vez se combinam, em grande parte, com a financeirização do risco associado às mudanças ambientais e atmosféricas, dentro do chamado "Mundo em Risco" (BECK, 2009). Esses processos se dão, segundo Sullivan (2012), via estratégias pelas quais as naturezas não humanas e dinâmicas da natureza vão sendo financeirizadas por meio de monetização, precificação e mercantilização, e dessa forma tornam-se mais um meio pelo qual o capital especulativo aposta em um valor a se realizar no futuro.

Destaca-se, também, as ações do Pacto Global da ONU. Esse representa uma iniciativa e chamado da Secretaria-Geral das Nações Unidas para empresas de todo o mundo para que alinhem suas operações e estratégias aos dez princípios universais nas áreas dos direitos humanos, trabalho, meio ambiente e anticorrupção. Essa iniciativa foi lançada em 2000, e visa, segundo a instituição, ajudar a comunidade global de negócios em avançar nos objetivos da ONU e nos valores por meio de práticas corporativas responsáveis. Quanto a sua magnitude o mesmo conta com mais de 9,5 mil empresas e 3 mil signatárias, que não são empresas, em mais de 160 países e 70 redes locais, é a maior associação de iniciativa sustentável no mundo.

o Desenvolvimento Internacional (USAID) no texto "Environmental and Natural Resource Management Framework". Esse document aponta o quadro de risco ligado a rápida perda da biodiversidade global e ao aumento da poluição de recursos críticos como a água e o ar, afirmando que diante disso estão em jogo o desenvolvimento econômico, a segurança alimentar, a saúde e a qualidade de vida de milhões. Levando a USAID a lançar "Environmental and Natural Resource Management Framework"
https://www.usaid.gov/sites/default/files/documents/1865/USAID_ENRM_FRAMEWORK.pdf. Acesso: 23 jul. 2020.

15 Segundo o Grupo ETC Group "New Bioeconomy" descreve a ideia de uma nova ordem industrial que se baseia em materiais, tecnologias e 'serviços' baseados em biologia. É um termo inventado pela indústria de biotecnologia, mas cada vez mais adotado por formuladores de políticas, tecnólogos e empresas globais de energia, silvicultura, agronegócio e química. Agora eles estão colaborando para construir essa visão de um futuro "verde" de alta tecnologia, usando técnicas como biologia sintética e nanotecnologia para transformar a "biomassa" viva em combustíveis, produtos químicos e energia. No entanto, o que é vendido como uma troca "verde" de combustíveis fósseis para produção baseada em plantas é, de fato, uma captura/expropriação em massa de recursos de terras, meios de subsistência, conhecimento e recursos do Sul global, onde $86 \%$ de toda a biomassa está localizada. A Bioeconomia está agora ameaçando a biodiversidade. Disponível em: http://www.etcgroup.org/issues/bioeconomy. Acesso: 23 jul. 2020.

16 Os ODS também fornecem uma estrutura para apoiar os negócios no gerenciamento de riscos e na identificação de oportunidades de mercado potencialmente históricas - https://www.wbcsd.org/Programs/People/Sustainable-DevelopmentGoals/SDG-Action-Policy

17 O evento em São Paulo teve o apoio da Pimco, B3, ONU Meio Ambiente, Fundo de População das Nações Unidas (UNFPA), Departamento de Assuntos Econômicos e Sociais das Nações Unidas (UNDESA) e Banco Itaú. Disponível em: https://nacoesunidas.org/sao-paulo-recebe-1o-forum-no-mundo-sobre-investimentos-nas-metas-sustentaveis-da-onu/. Acesso em: 15 maio 2020. 
Esses discursos assumem a forma de agendas políticas e econômicas defendidas/difundidas por organizações multilaterais (OMLs), ONGs, think tanks, consultores globais ${ }^{18}$ e toda uma expertise ligada ao planejamento econômico e sua busca pelo pretenso desenvolvimento ${ }^{19}$. Sobre a construção global de agendas políticas ou os ditos consensos, podemos nos valer de Oliveira (2006), o sociólogo aponta o papel da construção de consensos ligados a globalização. Para o autor, inspirando-se em Rancière (1996), política é a reclamação da parte dos que não têm parte e, por isso, se constitui em dissenso. Onde os que fazem política (atores transnacionais e grupos econômicos locais e nacionais) distinguem-se por pautar os movimentos do outro, do adversário, por impor-lhe, minimamente, uma agenda de questões, sobre as quais e em torno das quais se desenrola o conflito.

Contudo, essa imposição de agendas) "[...] não significa, necessariamente, ter êxito ou ganhar a disputa, antes, significa criar um campo específico dentro do qual o adversário é obrigado a mover-se" (OLIVEIRA, 2006, p. 265). Entende-se, nesse estudo, a sociedade do risco global (BECK, 2009) - assim como o capitalismo de catástrofe (KLEIN, 2008) - ligada ao paradigma das mudanças climáticas e seu discurso atrelado de desenvolvimento sustentável, economia verde, segurança alimentar, resiliência como campo específico de ação e construção de agendas e consensos quantos aos rumos da sociedade global.

\title{
MERCADO GLOBAL, FINANÇAS E MONOPÓLIO - OS CAMINHOS PARA A CRESCENTE MERCANTILIZAÇÃO DA NATUREZA E DESTRUIÇÃO CRIATIVA DA TERRA
}

Segundo Dowbor, analisando o comando do mercado global de commodities, que é muito importante para economias como a do Brasil e América Latina, aponta que o motor que movimenta seus preços é

\begin{abstract}
[...] a expectativa de ganhos especulativos dos traders, hoje 16 grupos que controlam o comércio mundial de commodities. Estes grupos, concentrados em Genebra, alimentam o chamado mercado de derivativos, que hoje é da ordem de 500 trilhões de dólares, para um PIB mundial de 80 trilhões. Neste sistema estão todos os grandes grupos financeiros mundiais, gerando imensa instabilidade tanto para os países produtores como para os países consumidores. (DOWBOR, 2017, p. 189).
\end{abstract}

Dados do relatório "Tecno-fusiones comestibles - Mapa del poder corporativo en la cadena alimentaria", do Grupo ETC (2019), mostram uma visão geral dos principais players em 10 setores do sistema alimentar: sementes, agroquímicos, fertilizantes sintéticos, máquinas para o agronegócio, farmacêuticos, animais, genética e pecuária, comerciantes de matérias-primas agrícolas, processamento de alimentos e bebidas, indústria de carnes / proteínas e varejo de alimentos. Apontam que os diferentes setores do sistema alimentar mundial - com um valor monetário acumulado de cerca de US \$ 8 trilhões, segundo analistas do Banco Mundial - são conhecidos há muito tempo como "elos da cadeia alimentar"20. O relatório ressalta algumas inovações disruptivas, que funcionam como as chamadas por Lazzarato (2015) "tecnologias de

18 Segundo a reportagem "Mercado de consultoria ambiental movimenta US $\$ 27,4$ bilhões" da revista Exame (2015) "O setor movimentou cerca de US\$27,4 bilhões em 2012, com um crescimento de $3,6 \%$ em relação ao ano anterior. [...] Segundo o estudo, divulgado este mês [jan. 2015], o mercado global de consultoria ambiental tem previsão de chegar aos US\$31,7 bilhões em 2017. Vinte e duas empresas lideram essa indústria. Em conjunto, elas representam $44 \%$ do total do mercado, diz o relatório. No topo da lista está a consultoria americana $\mathrm{CH} 2 \mathrm{M}$ Hill. A empresa integrou o consórcio responsável pelo planejamento, design e construção da infraestrutura dos Jogos Olímpicos de Londres 2012, que pleiteava o título de evento mais verde do tipo já realizado. Além dela, compõem a lista de 10 maiores consultorias da área a Tetra Tech, URS, Golder Associates, AECOM, Environmental Resources Management, Arcadis, AMEC Environment \& Infrastructure, MWH Global e Cardno. Disponível em: https://exame.abril.com.br/negocios/22-empresas-de-consultoria-lideram-mercado-verde-bilionario/. Acesso: 24 jul. 2020.

19 Para o geógrafo Carlos Walter Porto-Gonçalves o conceito de "desenvolvimento" é central na construção do paradigma da modernidade, e da própria construção do capitalismo. Sobre essa relação o mesmo aponta: "La crisis que experimenta la sociedade contemporânea es, y no podría ser de otro modo, una crisis de su magma de significaciones y, en este sentido, de su próprio concepto fundador. Precisamente en el momento en que este concepto era minado en sus cimentos, mostrándose insustentable, observábamos paradójicamente un intento por recuperarlo a través del adjetivo 'sustentable' associado al 'desarollo', tal como se consagra con la publicación del Informe Brundtland de 1987, bajo los auspícios de la ONU." (PORTOGONÇALVES, 2003, p. 07).

20 "Tecno-fusiones comestibles se refiere a una serie de disruptores tecnológicos y financieros que impulsan la consolidación y el poder corporativo en la gran industria de alimentos (Big Food). Estos disruptores tecnológicos y económicos intersectoriales incluyen las expansivas plataformas Big Data, la edición genética (por ejemplo, CRISPR Cas-9), las cadenas de bloques (blockchains) y la desmedida influencia de las firmas de gestión de activos". Disponível em: http://www.etcgroup.org/es/content/tecno-fusiones-comestibles. Acesso: 30 maio 2020. 
poder del capitalismo neoliberal', para pleno comando da produção da cadeia alimentar pelo poder corporativo como: plataformas expansivas de Big Data, edição de genes (por exemplo, CRISPR Cas-9), cadeias de blocos (blockchains).

Para Moyo (2013) o motor da crescente demanda por recursos naturais - commodificados - está ligado a lógica do sistema capitalista entre oferta e demanda. Sobre como isso se dá, atualmente, a autora afirma

[...] los factores que impulsan la oferta de tierra, agua, energia y minerales se complican por la existência de inter-relaciones entre los diferentes recursos. Por ejemplo, la oferta de alimentos - como los cereales y la carna de vacuno - depende fundamentalmente de la disponibilidade de tierras cultivables y de agua. Por ello, aceder a estos recursos subyacentes es casi tan importante como aceder a la própria mercancia y determina, en última instancia, el precio y la disponibilidade de una gama más amplia de produtos alimentícios. (MOYO, 2013, p. 25).

Assim como Moyo (2013) o estudo conjunto da PwC Suíça e WWF Suiça também afirma a ligação entre a biodiversidade e produção de mercadorias de toda sorte, sobre isso afirma: " $E$ particularmente perigoso para o setor financeiro não contabilizar a perda de biodiversidade, já que todos os setores econômicos nos quais investem, financiam ou seguram dependem da biodiversidade" (NATURAL CAPITAL COALITION, 2020). Os grandes grupos financeiros mundiais citados por Dowbor (2017) têm ampliado sua "fome de capital", devido a ampliação de algumas das principais contradições do sistema capitalista (HARVEY, 2014) como: as entre valor de uso e valor de troca; apropriação privada e riqueza comum e a formação dos desenvolvimentos geográficos desiguais e a tendência crescente ao monopólio versus a apologia da competição como motora do desenvolvimento. Tudo isso tem levado há um recrudescimento da destruição criativa da terra. (HARVEY, 2011).

Assim, tem-se a construção/imposição de uma nova governança global ou novos marcos institucionais e (re)regulatórios ligados a um regime de acumulação de dominância financeira (CHESNAIS, 1996; 2005). Nesse regime temos o atual papel das finanças globais e de suas capacidades de controle e mando, sobre isso Sassen (2016) aponta que as finanças podem adotar diferentes formas na superfície e se adaptarem a toda sorte de ambientes institucionais, a exemplo da China e Estados Unidos. Essa diversidade de formas pode se realizar com a realocação de um edifício, de uma commoditie e/ou bem comum, ou de uma dívida - pública ou privada - em um circuito financeiro em que estes se tornam móveis e podem ser comprados e vendidos inúmeras vezes ${ }^{21}$. Processo possível devido as tendências desses de bens naturais ou não se tornarem ativos econômicos. (AALBERS, 2017; SWYNGEDOUW; WARD, 2018).

Essa financeirização dá um novo "fôlego" para a dominação do capitalismo no tempo e no espaço, como afirma Belluzzo (2019)22. Esse "fôlego" se associa a algumas das mudanças/metamorfoses que o sistema tem exibido em sua grande capacidade/plasticidade para se adaptar ao espírito do tempo e fugir de suas crises e contradições, como algumas apontadas nesse texto, sobre isso Belluzzo afirma

Em minha modesta opinião, depois de libertado das disciplinas e amarras sociais que o domesticaram nos Trinta Anos Gloriosos do imediato pós-guerra, o velho capitalismo reconciliou-se com sua natureza inquieta e criativa. Tão inquieta e criativa que rapidamente transmutou a concorrência perfeita em concorrência monopolista. Livre, leve e solto em seu peculiar dinamismo, amparado em suas engrenagens tecnológicas e financeiras, o Velho Cap promoveu e promove a aceleração do tempo e o encolhimento do espaço. Esses fenômenos gêmeos podem ser observados na globalização, na financeirização e nos processos de produção da indústria 4.0. (BELLUZZO, 2019, p. 18).

Sobre essas transformações no sistema capitalista tem-se que as corporações mais poderosas procuram, cada vez mais, se libertar de quaisquer restrições - incluindo as de interesse comum e/ou social, ou de

21 Segundo dados do Grupo de Conjuntura da Fundação Perseu Abramo (2019) no seu estudo "Os donos do dinheiro - o rentismo no Brasil": "Calcula-se que a riqueza existente no mundo de hoje, por meio da soma dos PIBs de todos os países, seja algo em torno de 50 trilhões de dólares. O total de ativos seria três vezes maior, 150 trilhões de dólares, na realidade um valor virtual que alimenta o rentismo financeiro".

22 "O 'velho capitalismo' e seu fôlego para dominação do tempo e do espaço". Entrevista foi concedida ao Instituto Humanitas Unisinos - IHU. Publicada na revista IHU-On-Line, em 10 de junho de 2019. P. 12, Edição 537. 
interesse público local balizadas por regulações construídas via a lógica territorial do Estado (HARVEY, 2011), que interfiram em sua busca frenética por superlucros. Segundo Sassen (2016)

[...] as empresas têm novas ferramentas impressionantes [dispositivos] à sua disposição: matemática e comunicações avançadas, máquinas que literalmente podem mover montanhas, liberdade global de movimentos que nos (sic) permite ignorar ou intimidar governos nacionais, e cada vez mais instituições internacionais que impõem ao mundo inteiro o cumprimento de suas agendas. (SASSEN, 2016, p. 253, grifos do autor).

Ainda sobre o papel das finanças e de sua agenda global correlata Sassen (2016) afirma que não importa a geopolítica, a autoridade soberana, o sistema legal, nem a relação estado-economia, pois a lógica do capital financeiro insere-se "subterraneamente" em todos os espaços. Sobre isso a socióloga completa

Podemos pensar nas finanças como a mais completa e eficaz - ao menos a curto prazo - dessas tendências conceitualmente subterrâneas que estão reformulando o mundo de tantas maneiras diferentes. No caso das finanças, as manifestações visíveis adotam a forma de múltiplos micromundos e microtendências, alguns especializados, outros não: empréstimos de cartões de crédito, o déficit deste ou daquele governo, a dívida de determinada empresa, e assim por diante. (SASSEN. 2016, p. 145).

Brenner (2010) analisa a fase atual de reestruturação global induzida pela crise atual do sistema capitalista, onde o sistema busca um novo arranjo espacial e escalar, que por sua vez, estabelece um novo marco institucional - discursivo - e geográfico capaz de assegurar o processo de acumulação de capital dentro do quadro de maior competitividade internacional e mobilidade de capitais crescentes gerador de incertezas e riscos. Para Brenner (2010) isso ocasionou uma relativização da primazia da escala nacional e, simultaneamente, um maior reforço as ações das escalas supranacionais e subnacionais nesses processos. Podemos observar tais processos através da análise do crescimento do papel dos organismos multilaterais como: Banco Mundial - BIRD, Organização para a Cooperação e Desenvolvimento Económico - OCDE, Organização das Nações Unidas - ONU, Organização das Nações Unidas para Alimentação e Agricultura - FAO, entre outros na produção de programas, políticas, planos e ideias para o pretenso desenvolvimento, principalmente, de países do fordismo periférico no chamado Sul global (SOUSA SANTOS, 2010).

Com apoio dessas instituições dar-se um processo neoliberal de (re)regulações (BRENNER, PECK, THEODORE, 2012; STIGLITZ, 2017) nas novas legislações ligadas as questões: ambiental e agrária brasileira, como a Lei $n^{\circ}$ 12.651, de 2012 que dispõe sobre o Novo Código Florestal brasileiro. Essa lei possui dispositivos como o Programa de Regularização Ambiental (PRA), um dos instrumentos da Lei, que deverá ser implantado pelos Estados e Distrito Federal, para conduzir a adequação ambiental dos imóveis rurais e a inserção da sustentabilidade no setor agrícola, pecuário e silvicultural brasileiro. Atestese que essa chamada adequação nada mais é que a liberação e facilitação do câmbio desses recursos para ativos financeiros, presente no processo de assetização (AALBERS, 2017; SWYNGEDOUW; WARD, 2018).

Aponta-se também para a Lei 13.097 de 2015 ligada a governança das terras no Brasil, que segundo seus defensores trouxe mudanças importantes para os efeitos do registro de imóveis brasileiro, com potenciais ganhos para a segurança jurídica e para a governança fundiária. (REYDON; FERNANDES; BUENO, 2016). Leia-se que essas mudanças vão no sentido de modernizar o registro de imóveis brasileiro segundo a ótica da maior proteção da propriedade, pois o a governança corporativa moderna não admite falta de transparência em seus negócios, como forma de afastar e/ou reduzir os riscos econômicos e financeiros. Essa preocupação se apresenta no relatório da Climate Policy Initiative (CPI) "Insecure land rights in Brazil: consequences for rural areas and challenges for improvement", esse documento afirma que em 2015, o Brasil ficou em $95^{\circ}$, quanto aos direitos de propriedade segura no Índice Competitivo Global do Fórum Econômico Mundial (WEF). 
Destaca-se que o agronegócio ${ }^{23}$ para exportação é tido como o grande motor de nossa economia, recebendo toda sorte de incentivos via fundo público, fora medidas extra-econômicas como as (re)regulações quanto a liberação do uso intenso e crescente de agrotóxicos e mudança de legislações que tentam liberar o ativo terra para o mercado de terras global com medidas de governança de terras. Acontece que dentre os quatro motores da economia nacional: as exportações, a demanda das famílias, as iniciativas empresariais e as políticas públicas. As exportações segundo Dowbor (2017) não constituem nem de longe o principal motor da economia. Para o autor

\begin{abstract}
Os preços das commodities (Commodity Price Index), por exemplo, caíram 21,14\% nos 12 meses de abril 2015 a abril 2016, e as nossas exportações dependem muito destes produtos. Aqui, não há muito que possamos fazer, pois se trata da evolução do mercado mundial. Inclusive, as atividades para a exportação continuam firmes em termos de produção e volume, mas o que rendem é hoje muito menos. A monocultura de exportação, ao igual da mineração em grande escala, gera poucos empregos, e tem, portanto, um efeito limitado de dinamização pela demanda. Não é daí que virá a salvação da lavoura. Ainda que se trate de bens físicos como minério de ferro ou soja, o fato é que no plano internacional as variações são diretamente ligadas às atividades financeiras modernas [...]. (DOWBOR, 2017, p. 188-189).
\end{abstract}

Destaca-se com Dowbor (2017) que o baixo rendimento atual das exportações faz com que às mesmas tenham que aumentar sua escala de produção para auferirem mais lucros ou manterem os níveis de lucro, isso leva a uma maior apropriação e concentração de terras. Sobre a ligação da produção e comercialização dessas matérias-primas atrelada às atividades financeiras modernas ou ao chamado por Schumann "casino global de matérias primas", temos assim um modus operandi próprio dos mercados de futuro de matérias-primas que o autor explica da seguinte forma

\begin{abstract}
Los futuros sobre matérias primas son contratos estandardizados de operaciones a término gracias a los cuales los compradores y los vendedores acuerdan en forma anónima a través de la bolsa la entrega de una cantidad determinada de matérias primas en certa fecha y a un certo precio. Em general, estos contratos también estipulan en qué depósitos podrán ser entregadas y retiradas las mercaderías. No obstante, solo en casos excepcionales los contratos a plazo efetivamente se cumplen mediante la entrega del bien físico, ya que en la mayoría de los casos son gestionados financeiramente. En efecto, el comprador y el vendedor no celebran el negocio en forma directa. Lo hacen siempre a través de una bolsa que se convierte así para ambos en la parte contratante central. Por lo tanto, ademáas del comercio de las materias primas físicas, existe también un negocio puramente financeiro, pudiéndose realizar uno en forma independiente del outro. (SCHUMANN, 2014, p. 73-74).
\end{abstract}

Essa passagem do livro de Schumann (2014) aponta para o processo de "desabsolutização" das commodities, pois não se consubstancia a venda de bens físicos medidos em toneladas, por exemplo, ou determinado produto, mas sim uma comercialização de contratos associados a futuras rendas ligadas a essa commodities. Dentro desse quadro temos a atual corrida mundial por terras, fenômeno que se ampliou a partir da crise de $2007 / 2008$, que se liga as narrativas da segurança alimentar, essa por sua vez está relacionada mais a produção de commodities valorizadas no mercado do que a produção de alimentos realmente necessária, além de quebrar a soberania alimentar da população de países dependentes e periféricos. Essa corrida por terras foi denominada, inicialmente, por land grabbing e/ou acaparamiento de tierras, tema a ser discutido no próximo tópico.

\title{
LAND GRABBING, EXPROPRIAÇÃO DOS BENS COMUNS ESPACIAIS E A "LIQUEFAÇÃO" DA TERRA NA FORMA DE CAPITAL FICTÍCIO"
}

Segundo White et al (2012) citado por (BORRAS Jr. \& SAUER, 2016, p. 12), a expressão 'grabbing' designa tipos específicos na dinâmica de propriedade, "ou seja, a expropriação de terra, da água, de florestas e de outros recursos de propriedade comum; a sua concentração, privatização e transação (como propriedade ou aluguel) corporativas". Pereira (2017) afirma que o land grabbing "atualmente

23 Ver "Aliança Global do Agronegócio". Disponível em: https://www.wbcsd.org/Sector-Projects/Global-Agribusiness-Alliance. Acesso: 27 jul. 2020. 
ocorre em um contexto específico de convergência de crises - alimentar, ambiental, climática, energética e financeira - o que possibilita o surgimento de novos agentes, no caso os fundos de investimentos" (PEREIRA, 2017, p. 01, grifos do autor).

Frederico e Almeida (2019, p. 124) invocam o caráter transescalar do atual processo de land grabbing, sobre isso afirmam "[...] a articulação transescalar [é] imprescindível para a apropriação e o controle de terras. Desde os agentes vinculados ao tempo do mundo, como o capital financeiro internacional, até aqueles atrelados aos lugares, como latifundiários, políticos locais, tabeliões etc., sem desconsiderar o papel essencial do Estado e de empresas de âmbito nacional".

O processo atual de land grabbing vem "a reboque" da conformação do que Beck (2017) chama de "sociedade de risco mundial", ou como resultado do que Klein (2008) aponta em seu livro "A doutrina do choque" como a emergência de um "capitalismo de desastre". Tudo isso leva a uma "corrida" por terras que faz parte do contexto global recente explicitado na crescente demanda pelos chamados "4Fs": food (alimentos), fiber (fibras/ração), forest (floresta) e fuel (combustível ou energia). (BORRAS Jr.; SAUER, 2016).

Associa-se a isso o processo de oligopolização de setores como o setor agroalimentar, sobre essa oligopolização a IPES-Food e o Grupo ETC (2017) apontam:

\begin{abstract}
Las condiciones del mercado han sido especialmente propicias para la concentración en el sector agroalimentario. Después de la crisis financiera de 20072008 , los inversionistas se precipitaron hacia las mercancías agrícolas, em particular la tierra, lo que elevó los precios de los terrenos de cultivo. En lugar de comprar tierras como fuente inmediata para la producción de alimentos, los inversionistas compraron propiedades para diversificar sus carteras con el fin de protegerse contra los riesgos asumidos en otros mercados financieros. (IPES-FOOD \& ECT, 2017, p. 07).
\end{abstract}

Paralelo a isso, os governos latino-americanos passaram a destacar as vantagens comparativas do boom das commodities apoiados e influenciados pelos OMLs, defensores ideológicos dessa vantagem competitiva, esses últimos são os maiores ganhadores com a permanência das trocas desiguais, e realizam discursos que negam ou minimizam a produção de novas desigualdades econômicas e assimetrias, social, ambiental, territorial, associadas a exportação de matérias-primas em grande escala (SVAMPA, 2019). Svampa resume as consequências desse processo

Sin embargo, al calor del nuevo siglo XXI, el fenómeno del extractivismo adquirió nuevas dimensiones, no sólo objetivas -por la cantidad y la escala de los proyectos, los diferentes tipos de actividad, los actores nacionales y transnacionales involucrados-, sino también de otras subjetivas, a partir de la emergencia de grandes resistencias sociales, que cuestionaron el avance vertiginoso de la frontera de los commodities y fueron elaborando otros lenguajes y narrativas frente al despojo, en defensa de otros valores -la tierra, el territorio, los bienes comunes, la naturaleza ${ }^{24}$. (SVAMPA, 2019, p. 12).

Atualmente, no Brasil, uma das áreas que mais tem apresentado processos ligados ao fenômeno de land grabbing tem sido a região do MATOPIBA ${ }^{25}$ (BORRAS Jr. \& SAUER, 2016; PEREIRA, 2017; SEUFERT; MENDONÇA; PITTA, 2018; FERNANDES; FREDERICO; PEREIRA, 2019; FREDERICO; ALMEIDA, 2019). Essa área do Cerrado brasileiro que compreende os estados do Maranhão, Tocantins, Piauí e Bahia tem atraído grandes investimentos do exterior, os preços de terras na região

\footnotetext{
${ }^{24}$ Reportagem da organização Farmlandgrab aponta que "A fronteira agrícola do Brasil agora se estende profundamente nos estados do Cerrado como Maranhão, Tocantins, Piauí e Bahia - conhecidos coletivamente como Matopiba - e os conflitos são numerosos, de acordo com dados compilados exclusivamente para esta história da Comissão Pastoral da Terra da Igreja Católica, que rastreia terras conflitos no Brasil, Matopiba viu um aumento de 56 por cento nos conflitos de terra relatados (400 confrontos no total) durante o período de cinco anos, 2012-2016. Em contraste, o aumento nacional de conflitos no mesmo período foi de 21 por cento (com um total de 1.295 conflitos). Estatisticamente, os casos do Matopiba foram responsáveis por $30 \%$ de todos os conflitos. Só na Bahia, o número de confrontos disparou $61 \%$, com 86 confrontos ocorrendo lá. Disponível em: https://www.farmlandgrab.org/post/view/27990-cerrado-traditional-communities-accuse-agribusiness-of-green-land-grabbing. Acesso: 22 ago 2020.

${ }^{25}$ A região chamada MATOPIBA trata-se de uma região de cerrado entre o Maranhão, o Tocantins, o Piauí e a Bahia, considerada a última fronteira agrícola do país, foi delimitada pela Embrapa e o Incra como alvo de um projeto de desenvolvimento agropecuário. A presidenta Dilma Rousseff, assinou o Decreto 8.847, de maio de 2015, estabelecendo formalmente o Projeto Matopiba.
} 
subiram em alguns casos até $270 \%^{26}$. Esse modelo de exploração segue e atualiza o modelo agroextrativista para exportação presente no Programa de Cooperação Nipo-Brasileiro para o Desenvolvimento dos Cerrados - PRODECER, criado na década de 70 (FERNANDES, 2017), o desenvolvimento do MATOBIPA estaria ligado a atual fase financeira e neoliberal de desenvolvimento do campo brasileiro.

Esse movimento está relacionado a crescente atuação de empresas imobiliárias agrícolas financeirizadas, estas veem a terra como seu principal ativo financeiro, que se somam ao apetite dos fundos de investimento e demais investidores institucionais que passam a atuar no mercado de terras internacionais, principalmente no contexto pós-crise do subprime (HARVEY, 2011). O surgimento dessas empresas no país está relacionado, também, ao boom das commodities, e a recente corrida por terras de proporções globais, conhecido como land grabbing. (FERNANDES, 2017; FREDERICO; ALMEIDA, 2019; FERNANDES, FREDERICO; PEREIRA, 2019).

Ainda sobre a questão da análise transescalar da financeirização das terras do cerrado brasileiro e a consolidação de processos típicos de land grabbing, com destaque para a região do MATOPIBA, Fernandes, Frederico e Pereira (2019) escrevem:

O land grabbing mudou a questão agrária em escala mundial. No Brasil, uma região foi criada exclusivamente para atender aos interesses do capital financeiro em se territorializar para produzir commodities flexíveis. Esta nova realidade produziu o conceito de fronteira agrícola moderna caracterizada pela presença de uma agricultura intensiva em capital e tecnologia, em grandes áreas produzindo para exportação, com forte presença de tradings internacionais com o objetivo de se apropriar da renda fundiária.

Sobre a presença de uma agricultura intensiva em capital e tecnologia, em grandes áreas produzindo para exportação Seufert, Mendonça e Pitta (2018) assinalam que o processo de transformar a terra em um ativo financeiro global requer não apenas mudanças nas políticas e legislação, mas também o uso de tecnologias de informação ${ }^{27}$. Observa-se que existem novas característica para essa nova rodada de exploração e despossessão na/da América Latina e no/do Brasil, que apresenta uma exploração em larga escala ligada ao desenvolvimento de um meio técnico-científico-Informacional (SANTOS, 1996) que dá uma nova dimensão e poder para os agentes nacionais e internacionais envolvidos. ${ }^{28}$ Podemos associar a isso a Lei 13.097 de 2015 , ligada a governança das terras no Brasil, com grandes efeitos sobre o registro de imóveis brasileiro, com potenciais ganhos para a segurança jurídica e para a governança fundiária (REYDON; FERNANDES; BUENO, 2016; REYDON;

\footnotetext{
26 "Brasil é um dos cinco países do mundo que mais vende terra para estrangeiros". Disponível em: https://www.farmlandgrab.org/post/view/28201-brasil-e-um-dos-cinco-paises-do-mundo-que-mais-vende-terrapara-estrangeiros. Acesso: 26 ago. 2020.

27 "Financialization in general, and the financialization of land in particular, is linked in several ways to digitalization - i.e. the integration of digital technologies, based on the process of converting information into a digital format, also called 'digitization'. Firstly, the exponential growth of global finance over the last thirty years has only been possible because of information technology. Secondly, technical tools such as statistics, calculations on land use and productivity based on satellite images etc. have been used to transform land into an 'investible' resource, and to map those areas that are - supposedly - available for global investment. [...] Currently, several efforts are underway to apply the blockchain technology to land. Blockchain is the technology underlying cryptocurrencies like Bitcoin and is commonly described as an open, distributed/decentralized ledger that can record information and transactions between two parties "in a verifiable and permanent way". Pilot experiences are being carried out in different countries in all parts of the world, including Brazil" (SEUFERT; MENDONÇA; PITTA, 2018, p. 23).

${ }_{28}$ Sobre o uso concreto de novas tecnologias para uma possível ação de land grabbing ou de commodificação da natureza temos o artigo "Caça de dados na floresta de Mara e Mau" que relata: "Liderados por pesquisadores da Strathmore University Business School, do Institute for Global Prosperity da University College London e do PROCOL Kenya at the British Institute In Eastern Africa, as equipes de Mau e Mara estão construindo o primeiro bloco de dados das comunidades o Africa Regional Data Cube (ARDC). O ARDC, normalmente conhecido por fornecer acesso a dados espaciais prontos para o usuário, está permitindo que observações localizadas da terra sejam disponibilizadas para agências governamentais nacionais e internacionais, agricultores locais, moradores e idosos, por meio do uso de análises de Big Data. Os dados são coletados pelas comunidades por meio de aplicativos de smartphones, como Sapelli, que fornece geolocalização precisa, bem como um registro pictórico das espécies de árvores ou plantas, incluindo seu nome tradicional, tamanho e provisão de saúde. Ao fornecer observações precisas da terra, o mapeamento pode ser usado para projetar e criar cadeias de valor globais inovadoras, ligando as comunidades florestais locais Maasai e Mau aos mercados e amantes da natureza em todo o mundo. Disponível em: https://naturalcapitalcoalition.org/data-hunting-in-the-mara-and-mau-forest/. Acesso: 27 ago. 2020.
} 
FERNANDES, 2017) que para ser implementada precisa recorrer a construção do já apontado meio técnico-científico-informacional (SANTOS, 1996) ${ }^{29}$.

Para compreendermos um pouco desse poder da informação e das inovações tecnológicas nesse processo recorre-se ao trabalho de Pat Mooney e o Group ETC que publicaram "La insostenible Agricultura 4.0 - Digitalización y poder corporativo en la cadena alimentaria". Os autores tentam explicar como esse novo paradigma pode alterar de forma implacável as cadeias de valor ligadas a produção, distribuição e consumo de alimentos:

\begin{abstract}
[...] una de las comercializadoras de materias primas más antiguas del mundo, Louis Dreyfus, demostraba que con las plataformas Big Data se podían navegar las complejidades del comercio internacional sin papeles -y casi sin personas-, y no sólo para enviar soya, sino también para secuenciar ADN, aplicar agrotóxicos y comprar comestibles. Además de los "ceros y unos" con que se programan las computadoras, la novedad de la plataforma Big Data es que sus procesos automatizados y ultra veloces logran la assombrosa capacidad de manipular las cuatro bases de nucleótidos (A, C, G y T) de la doble hélice de ADN. Con el manejo de datos masivos del que son capaces los nuevos equipos de laboratorio, se puede acceder al mapa digital de un cereal etíope conservado genéticamente en Braunschweig, Alemania, desde una nube en Islandia, mediante un teclado en Ludwigshafen, donde se "edita" una secuencia de genes para construir remolachas tolerantes a la sequía para refinerías alemanas. Con la misma facilidad, la nueva plataforma Big Data le puede permitir a Nestlé em Suiza vincular los sonidos de camarones alimentándose en las costas de Alaska con terabytes de datos sobre los patrones climáticos de África occidental y las condiciones del suelo en América del Sur, para asegurar su posición privilegiada en los intercambios mercantiles de Chicago. (MOONEY \& GROUP ETC, 2018, p. 07)
\end{abstract}

Essas inovações da chamada Agricultura 4.0 servem para a gestão corporativa da cadeia alimentar industrial e segundo os autores podem se dividir em três grupos de inovação: "Hardware - La maquinaria agrícola de la Agricultura 4.0; Software - Los datos genómicos de la Agricultura 4.0; Fintech - Nuevas tecnologías de administración y finanzas" (MOONEY \& GROUP ETC, 2018). Aqui, chama-se atenção para o último grupo, que diretamente dialoga como nossos objetivos e apontam a emergência da governança corporativa global e tecnológica da natureza. Sobre o uso das Fintech os autores apontam

Una tercera dimensión en la que está enfocada la cadena alimentaria industrial son las tecnologías financieras, fintech en el argot, que incluyen blockchains y criptomonedas, herramientas de datos masivos que permiten a los actores clave administrar no sólo los eslabones individuales de la cadena alimentaria, sino también sus interrelaciones. [...] Las tecnologías blockchain no son exclusivas de los comerciantes multinacionales de productos básicos. Gobiernos, campesinos y cooperativas de productores también podrían usarlas. El gobierno del estado de Andhra Pradesh (India), por ejemplo, se ha comprometido a registrar en blockchain lo que describe como producción agroecológica. Para ello, se asoció con la empresa sueca ChromaWay para diseñar un sistema de blockchain para la documentación de títulos de tierras. En teoría, con blockchain em control de campesinos con teléfonos celulares, se podría eliminar a los intermediarios, a la vez que ahorraría tiempo y mejoraría los mercados. Si funciona, algunos esperan que una cadena de bloques pueda rastrear el flujo de los subsidios agrícolas de la India (con un valor de 4 mil 900 millones de dólares en 2017-2018), de modo que una mayor parte de los subsidios lleguen realmente a los campesinos. Una iniciativa similar está en construcción em Perú, donde empresarios de Silicon Valley han unido fuerzas con economistas locales para construir una blockchain para registrar los títulos de

\footnotetext{
${ }^{29}$ Para a maior governança da terra no Brasil temos também a instituição do Sistema Nacional de Gestão de Informações Territoriais - Sinter, por meio do Decreto $n^{\circ} 8.764$, de 10/05/2016, o qual se propõe a ser a ferramenta de gestão pública que realizará a integração entre os dados produzidos pelos serviços de registros públicos, e os dados fiscais, cadastrais e geoespaciais produzidos pela União, Estados, Municípios e Distrito Federal, incluindo cadastros já existentes, cuja proposta é a criação de uma estrutura computacional formada de camadas temáticas, nas quais se incluirão os registros de imóveis, a área fiscal, a governança fundiária, a produtividade da terra e demais dados sensíveis, indispensáveis à consecução de políticas governamentais. (REYDON; FERNANDES; BUENO, 2016). O objetivo expresso do referido decreto são a criação de um sistema de cadastro multifinalitário integrado e a regulamentação do artigo 41 da Lei Federal 11.977/2009.
} 
propiedad, con la esperanza de extender la tecnologia a una gama más amplia de transacciones mercantiles. Aunque las organizaciones locales de la sociedad civil sospechan con razón, el "Parque de la Papa" de Perú (una región agroecológica destinada a salvaguardar la agrobiodiversidad essencial y conservar la cultura, el conocimiento y los médios de subsistencia tradicionales) está ansioso por experimentar con su propio enfoque de blockchain controlado por sus miembros campesinos. (MOONEY \& GROUP ETC, 2018, p. 27).

Esses últimos usos de novas tecnologias para administração e finanças se aproximam das novas tecnologias de governo na governança de terras, como o Sistema Nacional de Gestão de Informações Territoriais - SINTER citado acima. E podem ser um dispositivo utilizado para futuros processos de land e green grabbing ${ }^{30}$. Também representam os dispositivos e as "tecnologias de poder del capitalismo neoliberal" apontadas aqui (LAZZARATO, 2015), ou uma nova conformação do que Santos (2002) chamou de meio técnico-científico-informacional.

Voltando a noção de land grabbing/acaparamiento de tierras, Harvey destaca a fundação de uma classe de rentistas (e proprietária), potencialmente poderosa, que regula o acesso a reserva de valores de uso em virtude do seu poder monopolista de classe e das rendas que ela extrai da terra. Assim, para o autor

El «acaparamiento de tierras» que se está llevando a cabo actualmente en todo el mundo (especialmente em África) tiene que ver más con la creciente competencia por monopolizar los recursos y la cadena alimentaria con vistas a la extracción de rentas que con el temor a unos inminentes límites naturales impuestos a la producción de alimentos y la extracción de minerales. El precio en aumento de los alimentos, que ha suscitado tanta inquietud últimamente, incluídas las revoluciones del norte de África, puede atribuirse mayoritariamente a la manera en que se está manipulando el sistema del valor de cambio por motivos de rentabilidad. (HARVEY, 2014, p. 246).

Dentro desse processo populações inteiras têm sido expulsas de seus territórios, ou tendo seus bens comuns expropriados. Sobre esse processo a socióloga Sassen (2016), no seu livro "Expulsões: brutalidade e complexidade na economia global", aponta que emerge uma maciça perda de habitat no hemisfério sul devido à expansão da mineração, do agronegócio, da disputa por água, da expansão das cidades. Isso tem gerado milhões de deslocados: camponeses, pequenos agricultores e populações rurais pobres, que representam para a mesma um novo tipo de refugiados, que são produzidos por uma forma particular de "desenvolvimento econômico", para nós essa forma particular faz parte do regime de acumulação capitalista com dominância financeira apontado por Chesnais. (CHESNAIS, 1996; PAULANI, 2008).

Por fim, destaca-se as alterações mais recentes no marco jurídico nacional sobre os processos de regularização de terras, como a criação e imposição da Medida Provisória 759, dezembro de 2016 (no período pós-golpe), a apelidada "MP da grilagem". Desta MP que sofreu uma série de alterações derivou-se a Lei 13.465/2017, que trata da regularização fundiária rural e urbana e da ocupação de terras da União na Amazônia Legal. A mesma modifica mais de uma dezena de leis ordinárias, muitas delas com mais de uma década de vigência elaboradas com ampla participação popular ${ }^{31}$. Destacase que em setembro de 2017, o procurador-geral da República, Rodrigo Janot, ajuizou no Supremo Tribunal Federal (STF) a Ação Direta de Inconstitucionalidade (ADI) $n^{\circ} 5771$. Essa medida pedia a

\footnotetext{
${ }^{30}$ Saweljew (2019) analisa o uso de técnicas da informação na captura da renda fundiária a partir da atuação de uma empresa agrícola, de capital aberto, que busca transformar a terra em ativo financeiro, essa empresa atua na região do Matopiba. $O$ autor destaca que empresas financeirizadas do agronegócio necessitam, para poderem se apropriar das faixas de terras mais produtivas, recorrer à informações precisas, daí fazem o uso de diversas técnicas da informação, como as imagens de satélite e o cruzamento de bancos de dados sobre a qualidade dos solos e os históricos de pluviosidade. Algumas empresas fazem "[...] uso da Big Data para o gerenciamento e captura de dados permite a essas empresas terem em tempo real, todo o cenário ativo do mercado de terras" (SAWELJEW, 2019, p. 86).

${ }^{31}$ Dentre as leis alteradas destacam-se: as Leis 8.629/1993 e 13.001/2014 (sobre reforma agrária), a Lei 8.666/1993 (sobre licitações), a Lei 11.952/2009 (que trata da chamada Amazônia Legal), a Lei 12.512/2011 (que trata do programa de apoio à conservação ambiental e o programa de foment às atividades produtivas rurais), a Lei 6.015/1973 (Registros Públicos) e a Lei 11.977/2009 (Minha Casa, Minha Vida), entre outras.
} 
inconstitucionalidade da Lei 13.465 , sancionada em julho de 2017. O procurador afirmava que a norma promove um retrocesso legislativo, favorecendo a grilagem de terras e o desmatamento ${ }^{32}$.

Segunda a Nota Técnica $n^{\circ}$ 1/2020/PFDC/MPF, de 3 de fevereiro de 2020, a Lei 13.465/2017 resultou em outra ação direta de inconstitucionalidade, a ADI 5778, lançada pelo Partido dos Trabalhadores. Segundo esta nota da Procuradoria Federal dos Direitos ao Cidadão - MPF ainda não houve julgamento pelo Supremo Tribunal Federal, e, em setembro de 2019, a então Procuradora-Geral da República manifestou-se, ao final, pela procedência de ambas as ações. (PFDC/MPF, 2020). Esses movimentos antidemocráticos ligados ao lançamento de medidas provisórias como as relatadas podem gerar novas rodadas de despossessão e expropriação de terras e bens comuns.

\title{
O MUNDO EM RISCO E O NOVO CAPITALISMO "VERDE" E FICTÍCIO: E A EMERGÊNCIA DO GREEN GRABBING E DA NATUREZA COMO ATIVO FINANCEIRO.
}

Para Mészáros existe uma incompatibilidade do capitalismo com o atendimento das necessidades reais das pessoas e sua autorreprodução. Para o autor, quanto mais aumenta a competitividade e a concorrência intercapitalista, mais nefastas são suas consequências, onde destaca: a destruição e/ou precarização, sem paralelos em toda a era moderna, da força humana que trabalha e a degradação crescente do meio ambiente, na relação metabólica entre homem, tecnologia e natureza, conduzida pela lógica societal subordinada aos parâmetros do capital e do sistema produtor de mercadorias. (MÉSZÁROS, 2011).

Assim, conforma-se o denominado "mundo em risco" (BECK, 2009), onde teríamos uma erosão progressiva e rápida da invulnerabilidade humana como legado das realizações científicas e técnicas da razão instrumental da modernidade industrial capitalista. Esse chamado "mundo em risco" para Harvey não assusta ao capital, para esse autor "[...] es perfectamente posible que el capital continúe circulando y acumulándose en medio de catástrofes medioambientales. Los desastres medioambientales generan abundantes oportunidades para que un "capitalismo del desastre» obtenga excelentes benefícios". (HARVEY, 2014, p. 244).

Sobre essa flexibilidade de atuação do capital financeiro que pode ter ganhos e superlucros com as consequências negativas para a sociedade das mudanças climáticas, Sassen afirma

\begin{abstract}
Um exemplo extremo é a criação de instrumentos que permitem a empresas financeiras apostar no crescimento de um setor e ao mesmo tempo apostar contra ele. Isso não vem a público, claro, mas às vezes podemos vislumbrar seu funcionamento. Recentemente, a Goldman Sachs criou derivativos para o governo grego que facilitavam a entrada da Grécia na União Europeia. Depois desenvolveram, para outro cliente, instrumentos que gerariam lucros se o governo da Grécia falisse ${ }^{33}$. (SASSEN, 2016, p. 164).
\end{abstract}

Tudo isso associa-se ao aumento da concorrência no capitalismo global monopolista entre as empresas no espaço global, que além de acelerar o processo de financeirização e concentração da riqueza e da renda - assim como dos recursos territoriais, agora visto como ativos, também submeteu os cidadãos a toda sorte de vulnerabilidades, exploração, angústias e insegurança. Tem-se que na era do capitalismo "turbinado" e financeirizado (BELLUZZO, 2019), os frutos do crescimento se concentraram nas mãos dos detentores de carteiras de títulos, que como veremos nesse artigo incluem recursos territoriais (água, terras, florestas, minérios etc.).

Sobre a transformação da natureza e de bens comuns em mercadorias destaca-se livro organizados por Fletcher, Dressler e Büscher (2014) "Nature inc.: environmental conservation in the neoliberal age" que reúne uma série de artigos com análises críticas sobre temas ligados a imbricação entre a expansão capitalista e processos de neoliberalização, que apontam para uma crescente mercantilização,

\footnotetext{
32 Mais informações em "\#RetrocessoAmbientalNão: PGR pede inconstitucionalidade de lei que favorece grilagem e desmatamento na Amazônia". Disponível em: http://pfdc.pgr.mpf.mp.br/informativos/edicoes2017/setembro/retrocessoambientalnao-pgr-pede-inconstitucionalidade-de-lei-que-favorece-grilagem-e-desmatamento-naamazonia. Acesso: 21 out. 2020.

33 Para mais informações sobre o papel das finanças globais na crise financeira grega ler: "El sintoma griego: posdemocracia, guerra monetária y resistência social em la Europa de hoy" (BABIOU; RANCIÉRE; NEGRI Et al. 2013).
} 
financeirização e disciplina de mercado para bens como terras, biodiversidade etc. Os autores assinalam questões ligadas a conservação ambiental, ecoturismo, pagamentos por serviços ambientais e derivativos ligados a biodiversidade, destaca-se também uma variedade de novos instrumentos financeiros e tecnológicos, como banco de espécies, comércio de carbono, entre outros. Procuram apresentar e avaliar os mecanismos que passam a transcender a tradicional conservação de recursos naturais particulares in locu e passam a permitir a abstração e circulação do "capital natural" em toda economia global. (FLETCHER, DRESSLER, BÜSCHER, 2014) ${ }^{34}$.

Como exemplo da defesa da produção de carteiras de títulos com recursos territoriais aponta-se as ações da instituição estadunidense Property and Environment Research Center - PERC, que se apresenta como um instituto de conservação e pesquisa dedicado ao ambientalismo de mercado livre. Nesse instituto são realizadas pesquisas que examinam: "como os mercados encorajam a cooperação em vez do conflito sobre os recursos naturais e como os direitos de propriedade tornam o meio ambiente um ativo, dando aos proprietários incentivos para a administração"35. Aqui ver-se mais uma vez a narrativa da busca da assetização da natureza, ou seja, sua transformação em ativos financeiros.

Beck (2017) aponta que na sociedade do risco mundial os maiores produtores do risco discutem entre si sobre suas características, causas e consequências, assim como desenham as melhores definições e soluções para as demais nações e população mundial, as chamadas "boas práticas" (dispositivos). Para os agentes globais os países periféricos não estão preparados para a sociedade de risco mundial (BECK, 2017). Esses agentes defendem a mercantilização e privatização desses recursos como única forma de conservá-los. Observa-se a construção de narrativas, métricas, valores ligados a transfiguração de bens comuns em capitais fictícios, a exemplo temos materiais produzidos por organismos multilaterais, consultorias e think thanks ligados a esse processo, como o "Guía para la Valoración Corporativa de los Ecosistemas", produzido pelo World Business Council for Sustainable Development (WBCSD) ${ }^{36}$, com a parceria da PricewaterhouseCoopers - PwC. (WBCSD, 2011).

Assim, tem-se a construção do consenso global, presente de forma disfarçada no chamado "diálogo" cada vez mais despolitizado. No tocante a formação de consenso quanto as mudanças climáticas e seus impactos no aquecimento global tivemos o papel dos relatórios do Painel Intergovernamental sobre Mudanças Climáticas (Intergovernmental Panel on Climate Change, IPCC ${ }^{37}$ ), organismo internacional criado em 1988 pela Organização das Nações Unidas - ONU para o Meio Ambiente (PNUMA) e a Organização Mundial de Meteorologia (OMM) para avaliar os estudos científicos sobre as mudanças climáticas e seus efeitos socioeconômicos. (FURTADO, 2015).

Alude-se para a construção de consensos ou de um "senso comum" quanto ao papel das mudanças climáticas elaborado via os dados do IPCC, que são utilizados por governos de países centrais, organização multilaterais, para provar a existência e perigo de uma crise climática cujo diagnóstico permitiria o estabelecimento de medidas, metas, instituições e políticas para o seu enfrentamento, aqui chamados de dispositivos de comando, controle e difusão de soluções via mercado para o enfrentamento

\footnotetext{
34 Os autores apontam como resultado dessa confluência: "Considered together, these dynamics have produced a truly global conservation frontier: a suite of networks, activities, and regulations that are rapidly changing the relations between people and nature worldwide. This frontier traverses and connects the boardrooms of global hedge funds, trees owned by small farmers, consumers, interest groups, giant nature reserves, and a myriad of species (both human and nonhuman) trying to survive in changing ecologies. It boasts grand images of pristine landscapes connected to often contradictory material realities and consequences, leaving some actors struggling to access new markets and others dispossessed by various "green grabs" (see Fairhead, Leach, and Scoones 2012b). Building on Arsel and Büscher (2012), we refer to these new frontiers of neoliberal conservation as "Nature TM Inc.". (FLETCHER, DRESSLER, BÜSCHER, 2014, p. 05).

35 Centro de Pesquisa de Propriedade e Meio Ambiente - é um instituto de conservação e pesquisa dedicado ao ambientalismo de livre mercado. Disponível em: https://www.perc.org/about-us/. Acesso: 15 ago. 2020.

${ }^{36}$ A WBCSD já possui certo portfólio na construção de dispositivos (índices, métricas, valores) no sentido de mercantilização e commodificação da natureza, onde destaca-se: a Global Water Tool, o GHG Protocol e o Corporate Ecosystem Services Review. (WBCSD, 2011).

37 Painel Intergovernamental de Mudanças Climáticas (IPCC): O IPCC é um órgão científico. Ele analisa e avalia as informações científicas, técnicas e socioeconômicas mais recentes produzidas em todo o mundo, relevantes para o entendimento das mudanças climáticas. Foi estabelecido pelo Programa das Nações Unidas para o Meio Ambiente (PNUMA) e pela Organização Meteorológica Mundial (OMM) para fornecer ao mundo uma visão científica clara do estado atual do conhecimento em mudanças climáticas e seus potenciais impactos ambientais e socioeconômicos.
} 
das mudanças climáticas. Assim foram realizadas diversas conferências, onde destaca-se a $21^{a}$ Conferência das Partes (COP-21) da CQNUMC ${ }^{38}$, sediada em Paris, em 2015.

As discussões sobre o aquecimento global chegam, de forma mais efetiva, aos povos do Sul Global (SANTOS, 2010) a partir do diagnóstico científico da Convenção-Quadro das Nações Unidas sobre Mudanças Climáticas (CQNUMC), que aponta o desmatamento como uma das principais fontes de emissões de GEE, inicia-se um debate sobre mecanismos institucionais para a conservação florestal ${ }^{39}$. Após isso as florestas passam a serem percebidas como estoque de carbono (e de capital), o que torna possível evitar a implementação de medidas de redução de emissões por parte dos países do Atlântico Norte, pois a conservação de florestas dos povos do Sul Global seria capaz de resolver essa limitação indesejada no norte, e ao mesmo tempo beneficiar econômica e politicamente os países periféricos e dependentes sempre atolados em dívidas. Dessa forma, desde o Protocolo de Kyoto, em 1997, foi proposto o mercado de créditos de carbono como instrumento de redução das emissões de GEE.

Sobre as narrativas em torno dos mecanismos financeiros ligados a emissões de GEE e a criação de mercados de carbono Böhm, Misoczky e Moog (2012) apontam suas principais contradições. Esses dispositivos tratam-se de modos criativos de acumulação primitiva, e é pouco provável que se transformem, realmente, em uma economia global mais sustentável. Para esses autores os mercados de carbono atuam na exacerbação do desenvolvimento desigual no Sul Global, à medida que suas elites alavancam o financiamento do mercado de carbono para buscar novas estratégias de expansão subimperial e acumulação primitiva, tudo isso leva a reprodução de tendências contínuas de mercantilização e expropriação ecológica, conduzindo processos de desenvolvimento geográfico e desigual ${ }^{40}$. Nesse contexto, emerge a proposta de mecanismos de Redução de Emissão por Desmatamento e Degradação $(\text { REDD }+)^{41}$, que incluem investimentos públicos e privados em manejo, conservação e aumento de estoque de carbono florestal. O governo brasileiro em 2011, iniciou um processo de definição de uma estratégia nacional de REDD+. O artigo 41 do capítulo $X$ da Lei $n^{\circ} 12.651$ aponta para o Pagamento de Serviços Ambientais (PSA), como instrumento de apoio e incentivo à conservação do meio ambiente. Ressalta-se a conformação de normas, inovações financeiras e institucionalidades para tais propósitos como se analisará mais à frente no texto.

A conversão da natureza em dividendos para o capital financeiro se dá por uma série de instrumentos/dispositivos e inovações financeiras. Dentre as quais temos as ligadas ao mercado de carbono, fundado na noção de "direito de emitir" baseado no sistema "limite e comércio" (cap \& trade, em inglês). Esse funciona através da comercialização de uma mercadoria (fictícia) criada a partir dos limites de quantidade de moléculas de carbono que podem ser emitidas, segundo estimativa e cálculo baseados no chamado Potencial de Aquecimento Global (Global Warming Potential, em inglês) (FURTADO, 2015). Algo que nos chama a atenção é o fato da desobrigação do agente poluidor em reduzir suas emissões para atingir a meta estabelecida, pois empresas podem comprar créditos de carbono gerados por outras empresas cujas emissões são inferiores à meta quantitativa fixada. Recentemente tem se realizado uma profusão de criação e difusão de "green bonds" ou "títulos verdes" ligados a fluxos financeiros públicos e

\footnotetext{
38 A Convenção-Quadro das Nações Unidas sobre Mudança do Clima, foi assinada em Nova York, em 9 de maio de 1992. Disponível em: http://www.planalto.gov.br/ccivil 03/decreto/d2652.htm. Acesso: 16 ago. 2020.

${ }^{39}$ A redução das emissões por desmatamento e degradação florestal e o papel da conservação, manejo sustentável de florestas e aumento dos estoques de carbono florestal nos países em desenvolvimento ( REDD + ) foram negociados pela Convenção Quadro das Nações Unidas sobre Mudanças Climáticas (UNFCCC) em 2005, com o objetivo de mitigar a mudança climática através da redução das emissões líquidas de gases de efeito estufa através de uma melhor gestão das florestas nos países em desenvolvimento.

${ }^{40}$ Sobre a política subimperialista de países como Brasil no continente africano ligados a estratégias como a REDD+ assinalase o casa de Moçambique que após a crise do subprime abriu a suas fronteiras para processos de land grabbing. De acordo com matéria do International Institute for Environment and Development: "Empresas europeias e norte-americanas têm adquirido terras para cultivar safras de exportação e biocombustíveis e suprir suas necessidades de celulose e papel. Agora eles estão sendo acompanhados por economias emergentes - em particular Brasil, Índia e China - que também estão adquirindo cada vez mais grandes extensões de terra e procurando outros recursos naturais, em particular água e minerais". Disponível em: https://www.iied.org/redd-mozambique-new-opportunity-for-land-grabbers. Acesso: 20 ago. 2020.

${ }^{41}$ Destaca-se que o dispositivo REDD+ é um incentivo desenvolvido no âmbito da Convenção-Quadro das Nações Unidas sobre Mudança do Clima (UNFCCC) para recompensar financeiramente países em desenvolvimento por seus resultados de Redução de Emissões de gases de efeito estufa provenientes do Desmatamento e da Degradação florestal, considerando o papel da conservação de estoques de carbono florestal, manejo sustentável de florestas e aumento de estoques de carbono florestal (+). Disponivel em: http://redd.mma.gov.br/pt/pub-apresentacoes/item/82-o-que-e-redd. Acesso: 11 ago. 2020.
} 
privados para investimentos e atividades que reduzem as emissões de carbono ou aumentam a resiliência aos impactos das mudanças climáticas (ASOCIACIÓN LATINOAMERICANA DE INSTITUCIONES FINANCIERAS PARA EL DESARROLLO - ALIDE, 2019), uma das instituições promotoras desse mercado é o Grupo de Estudio de Finanzas Verdes del G20 (GFSG).

Destaca-se o papel das OMLs, a exemplo das ações do Grupo Banco Mundial e seu papel de liderança, participando das negociações, apresentando metodologias de precificação da natureza, além de gerir fundos e financiar projetos relacionado ao mercado de carbono. Sobre esse papel Furtado explica

\begin{abstract}
Neste contexto, instituições multilaterais, como o Banco Mundial, assumem um papel de liderança, participando das negociações, apresentando metodologias de precificação da natureza, gerindo fundos e financiando projetos relacionado ao mercado de carbono e REDD+. O Banco Mundial foi responsável pelo Estudo de Baixo Carbono para o Brasil em 2010, publica relatórios anuais sobre a situação do mercado de carbono no mundo como a recente publicação "Mapeando iniciativas de precificação do carbono" (Mapping carbon pricing initiatives) e administra 15 fundos de carbono. (FURTADO, 2015, p. 24).
\end{abstract}

Outra narrativa está ligada a mudança de valores associados a conservação da natureza e da biodiversidade ${ }^{42}$, ou da própria forma de valoração/precificação da natureza, tem-se a oposição entre a teoria do valor intrínseco e a teoria económica (DEMPSEY; COLLARD; 2013; DEMPSEY; ROBERTSON, 2013; APOSTOLOPOULOU; ADAMS, 2015; DEMPSEY, 2016). Sobre essas mudanças Muniz (2019) afirma

É uma mudança discursiva que tem levado a novas formas de perceber e de se relacionar com o mundo natural não-humano em maneira estritamente econômica, sobretudo financeira. É também uma mudança institucional que induz os arranjos institucionais (redes e alianças entre o mundo corporativo, financeiro e conservacionista) a se acomodarem na tarefa de tornar reais as metáforas do 'capital natural' e dos 'serviços ecossistêmicos'. É ainda uma mudança técnica e material que visa fragmentar a natureza, assinalar valores monetários aos seus 'fragmentos' e facilitar sua transação através de instrumentos baseados no mercado. A natureza, dessa forma passa a ser transcrita em bens e serviços passíveis de quantificação, transação, degradação e compensação para que, de um modo geral, os danos ambientais possam ser minimizados. (MUNIZ, 2019, p. 43)

Ações ligadas ao estímulo a compensação ambiental têm sido apropriadas e desvirtuadas de sentido pelo mercado. Sobre isso, Bernardo \& Nogueira (2016), escrevem sobre as contradições da política de criação e manutenção de Unidades de Conservação - UCs brasileiras:

A criação de UCs surgiu da necessidade de manter a diversidade biológica para usufruto da população atual e futura, já que os recursos ambientais são fonte de diversos bens e serviços utilizados dentro de uma cesta de consumo na provisão do bem-estar individual e social. [...] a compensação ambiental é um instrumento financeiro utilizado para compensar a externalidade negativa dos danos futuros que serão causados pelos empreendimentos. [...] Assim, é estranho ter um instrumento de financiamento de UCs que seja vinculado a atividades que degradam o meio ambiente, em que a política relacionada a ele é exatamente contrária à degradação. Dessa maneira, cria-se um conflito na gestão ambiental: quanto mais poluente o empreendimento, melhor em termos financeiros, mas pior para o ambiente e sociedade local, porque esse dinheiro não é usado in loco. (BERNADO \& NOGUEIRA, 2016, s/p).

42 Entende-se aqui a Biodiversidade como diversidade biológica que se refere a todos os organismos vivos, seu material genético e os ecossistemas dos quais fazem parte. Geralmente é descrito em três níveis: genético, espécie e ecossistema. A perda de diversidade cultural (incluindo idiomas) e o conhecimento tradicional - de comunidades agrícolas e culturas indígenas - está intrinsecamente ligada à perda de diversidade biológica. Portanto, práticas de land/green grabbing podem levar a essa perda e à transformação de todo esse potencial em ativos econômicos e financeiros.

43 Para Harvey (1996) a história de como os seres humanos passaram a valorizar o mundo natural é longa e intricada. Dentro dela o autor destaca o papel da Economia Política burguesa afirmando: "A economia política burguesa - filha do pensamento do século XVIII - articulou a visão da natureza como "recurso" e atribuiu a si mesmo a principal tarefa teórica de determinar a alocação racional de recursos que eram escassos. Para isso, apelou à teoria dos mercados, aos objetivos de maximizar a utilidade e à centralidade do dinheiro como meio comum de medir heterogeneidades dos desejos humanos, dos valores de uso e dos elementos e processos "na natureza"' (HARVEY, 1996, p. 150 [Trad. do Autor]). 
É oportuno, também, mostrar as oportunidades abertas para investimentos e empréstimos dentro do novo mercado global ligado aos desastres e riscos ambientais, pois, na perspectiva defendida nesse artigo, essas são, na realidade, o principal leitmotiv para tamanha importância dada ao tema. Para tanto o paradigma das mudanças climáticas é a base da maioria das propostas de financiamento, empréstimos e securitizações. A instituição internacional Natural Capital Coalition (2020) citando o estudo 'A natureza é grande demais para falir - Biodiversidade: a próxima fronteira na gestão de risco financeiro' da PwC Suíça e o WWF Suíça aponta que foram descobertos riscos financeiros associados à perda de biodiversidade que podem se tornar críticos $^{44}$. O mesmo discurso se encontra no documento "Mercado de Bonos Verdes: ¿quiénes son sus protagonistas?" da ALIDE, entidade pertencente ao G20. (ALIDE, 2019).

No presente estudo aponta-se para a construção de meios para integrar as perdas de biodiversidade à estrutura clássica de risco das instituições financeiras, ou o que chamamos nesse estudo para a construção de meios para a assetização da natureza (BIRCH, 2016; SWYNGEDOUW; WARD, 2018). O relatório da PWC Suíça e WWF Suíça sugere também que todos os atores financeiros devem gerenciar de forma proativa seus riscos financeiros relacionados à biodiversidade, assim como aproveitar e garantir as oportunidades oferecidas pelos serviços ecossistêmicos (por exemplo, proteção contra enchentes, polinização, água potável, solos férteis e adaptação às mudanças climáticas). Ver-se aqui a tendência a novas rodadas de despossessão, mercantilização e privatização da natureza e/ou dos bens comuns espaciais (STANDING, 2017).

Destaca-se que Foster \& Clarck (2006, p. 02) assinalam que "Marx afirmava em sua própria obra- que as transferências de valor econômico são acompanhadas de maneira complexa por fluxos "ecológicomateriais" reais que transformam as relações entre o campo e a cidade, e entre as metrópoles globais e a periferia. O controle de tais fluxos é uma parte vital da competição entre os centros industriais e financeiros rivais". Harvey (2014) ver o capitalismo como um sistema ecológico em constante funcionamento e evolução dentro do qual tanto a natureza como o capital se produzem e reproduzem continuamente, como pudemos ver com as novas iniciativas e inovações financeiras ligadas a questão ambiental global ${ }^{45}$.

No Brasil, ressalta-se o papel da Lei $n^{\circ} 12.651 / 2012$, que dispõe sobre o Novo Código Florestal brasileiro (PACKER, 2015; FURTADO, 2015). Essa lei possui dispositivos ligados a adequação ambiental dos imóveis rurais e a inserção da sustentabilidade no setor agrícola, pecuário e silvicultural brasileiro. Trata-se da liberação e facilitação do câmbio desses recursos para ativos financeiros, o que chamamos nesse artigo de assetização (BIRCH, 2016; AALBERS, 2017; WARD \& SWYNGEDOUW, 2018). Para tanto é necessária uma maior carga de informação e controle sobre as terras e sobre os chamados serviços ambientais/ecossistêmicos ${ }^{46}$ que se dá via práticas (dispositivos) de accountability ligadas a governança corporativa neoliberal das terras e da natureza ${ }^{47}$.

\footnotetext{
${ }^{44}$ Pode-se observer esse discurso na reportagem "Por que a crise que envolve a natureza é importante para os negócios e a economia" da Natural Capital Coalition, instituição auto declarada líder global na integração de abordagens de capital natural no setor privado, essa instituição lançou, em 2016, o Natural Capital Protocol. Disponível em: https://naturalcapitalcoalition.org/why-the-crisis-engulfing-nature-matters-for-business-and-the-economy/. Acesso: 10 ago. 2020. Também encontrou-se tal narrativa no texto: "A natureza é grande demais para falir: os atores financeiros precisam agir rapidamente", também da Natural Capital Coalition. Disponível em: https://naturalcapitalcoalition.org/nature-is-too-big-to-failfinancial-actors-need-to-act-swiftly/. Acesso: 10 ago. 2020.

45 Harvey (2014) acredita que dentro da atual fase financeira do capitalismo: "[...] el capital ha convertido los asuntos medioambientales en una gran área de actividad empresarial. Las tecnologías ambientales cotizan actualmente al alza en las bolsas mundiales. Una vez que esto ocurre, como en el caso de la tecnología en general, la configuración de la relación metabólica con la naturaleza se convierte en una actividad autónoma frente a las auténticas necesidades reales. La naturaleza se convierte, de nuevo según Neil Smith, en "una estrategia de acumulación"”. (HARVEY, 2014, p. 243).

46 De acordo com a ONU-Habitat (2015) "Serviços ecossistêmicos são definidos como benefícios conferidos pelos ecossistemas às pessoas, delineados em quatro categorias: serviços de suporte (ex.: habitat para as espécies e recursos genéticos), serviços de provisão ou abastecimento (ex.: alimentos e recursos médicos), serviços de regulação (ex.: regulagem do clima local e de eventos extremos) e serviços culturais (ex.: recreação e turismo). (ONU-HABITAT, 2015, p. 1-2).

47 A cotização da natureza, também, é elaborada via padrões métricos como índices ligados ao discurso/paradigma da governança corporativa, seja ambiental, de terras etc. como o "Índice de la Gobernanza de los Recursos Naturales 2017" apresentado pela Natural Resource Governance Institute (2017). Sobre a necessidade de construção do mesmo o instituto aponta para a importância da gestão eficiente, eficaz, sustentável e transparente dos recursos naturais, com destaque para a extração de petróleo, gás e minerais, que passa a ser uma das explorações mais complexas em termos políticos, sociais, ambientais e econômicos para o pretenso desenvolvimento. Essa exploração pode levar a contexto e medidas pósdemocráticas em países dependentes e periféricos.
} 
O governo brasileiro, seguindo exigência da CQNUMC, em dezembro de 2008, apresentou um Plano Nacional de Mudanças Climáticas contendo medidas de mitigação e adaptação ${ }^{48}$. Em 2009 instituiu a Política Nacional sobre a Mudança do Clima. Já em 2011, iniciou um processo de definição de uma estratégia nacional de REDD+. Observa-se que o artigo 41 do capítulo X da Lei $n^{\circ} 12.651^{49}$, de 2012 (Novo Código Florestal) aponta para o Pagamento de Serviços Ambientais (PSA), como instrumento de apoio e incentivo à conservação do meio ambiente, e inclui em nossa legislação a Cota de Reserva Ambiental (CRA), "título representativo de vegetação nativa" que pode ser comercializada entre produtores que superam o nível estabelecido de manutenção da reserva legal e os que não a mantém. Ressalta-se que o enquadramento crescente da "natureza" como um "provedor de serviços" vem sendo promovido, como maior ênfase, desde a Convenção sobre Diversidade Biológica - CDB, ocorrida no Brasil, em 1992, na chamada Rio 92. (FLETCHER, DRESSLER, BÜSCHER, 2014).

Sobre isso Silveira \& Muniz afirmam

A legislação brasileira recente, Lei $n^{\circ} 12.651$ (BRASIL, 2012a), alterada pela Lei $n^{\circ}$ 12.727 (BRASIL,2012b) prevê o pagamento por serviços ambientais (PSA), trazendo uma diferenciação entre os serviços difusos prestados pelos ecossistemas, de serviços prestados por áreas conservadas, numa escala reduzida dos serviços ecossistêmicos. Os serviços ambientais, assim, têm os agentes fornecedores de ativos ambientais identificados nos proprietários de áreas conservadas. [...]Nessa concepção, PSA é uma proposta de estruturar um mercado onde seriam negociados os ativos e serviços ambientais por aqueles que os mantêm, e aqueles que deles necessitam para atender a legislação. (SILVEIRA \& MUNIZ, 2014, p. 17).

Destaca-se que o capitalismo está pleno de desenvolvimentos geográficos desiguais baseados nas trocas desiguais (SOJA, 1993), inclusive com transferências de benefício ecológicos de países periféricos para países centrais, que nem sempre contam com o consenso dos primeiros. Essa transferência representa um corolário do que Foster \& Clark (2006) chamam de "Imperialismo Ecológico"50. Quanto a isso Harvey aponta

La transferencia de los beneficios ecológicos de una parte del mundo a otra entraña tensiones geopolíticas. Esto también contribuye a explicar por qué el enfoque boliviano y ecuatoriano respecto al uso de "su naturaleza» es tan radicalmente diferente del de Estados Unidos. Los bolivianos y los ecuatorianos quieren mantener su petróleo en el subsuelo. ¿Por qué permitir su extracción para que se utilice, por ejemplo, en Estados Unidos a cambio de recibir una miseria en royalties? ¿Por qué deberían mis recursos subsidiar tu tren de vida? (HARVEY, 2014, p. 251).

O documento da Natural Resource Governance Institute (2017) sobre a governança dos recursos naturais afirma que "Es un negocio que conecta al mundo y satisface buena parte de nuestro hambre de energía y materias primas. Produce insumos para casi todo producto físico manufacturado. $\mathrm{Ha}$ contribuido a uno de los desafios fundamentales de la historia humana: el cambio climático. Ha generado billones de dólares en ingressos". (NATURAL RESOURCE GOVERNANCE INSTITUTE, 2017, p. 03).

Acontece que essa satisfação da fome de energia e matérias-primas tem proporcionado um novo arranjo espacial exploratório voltado a atuar fortemente nos países (semi)periféricos e dependentes. Fato que tem gerado a ampliação das fronteiras do neoextrativismo nesses países (SVAMPA, 2019) que representa para nós o crescimento da "fome do capital" que consome lugares em larga escala -

48 Destaca-se que desde 2007 tramita na Câmara dos Deputados o PL 792/2007, que dispõe sobre e define os serviços ambientais e prevê a transferência de recursos, monetários ou não, aos que ajudam a produzir ou conservar estes serviços. 0 mesmo foi discutido pela última vez em julho de 2019. Disponível em: https://www.camara.leg.br/proposicoesWeb/fichadetramitacao?idProposicao=348783. Acesso: 22 ago. 2020.

49 Destaca-se que essa lei foi alterada pela Lei $N^{\circ} 12.727$, de 17 de outubro de 2012 . Onde destaca-se o seu Art. $1^{\circ}$ que afirma que a Lei $n^{\circ} 12.651$, de 25 de maio de 2012, passa a vigorar com as seguintes alterações: "Art. $1^{\circ}$ - A. Esta Lei estabelece normas gerais sobre a proteção da vegetação, áreas de Preservação Permanente e as áreas de Reserva Legal; a exploração florestal, o suprimento de matéria-prima florestal, o controle da origem dos produtos florestais e o controle e prevenção dos incêndios florestais, e prevê instrumentos econômicos e financeiros para o alcance de seus objetivos". (BRASIL, 2012).

${ }^{50}$ Os autores apontam que esse termo se origina "Em 1986, Alfred Crosby publicou um livro intitulado Ecological Imperialism: The Biological Expansion of Europe, 900-1900, no qual descrevia a destruição - geralmente inadvertida- do meio-ambiente indígena através da colonização européia de grande parte do resto do mundo". (FOSTER; CLARCK, 2006, p. 01). 
renova-se a analogia feita por Polanyi sobre a economia de mercado funcionar como um moinho satânico.

Paralelo a essa ofensiva do capital sobre os bens comuns temos o surgimento da expressão "green grabbing" (FAIRHEAD; LEACH; SCOONES, 2012) ou "grilagem verde" que para Borras Jr. \& Sauer (2016, p. 26, grifos do autor) se apresenta como

\begin{abstract}
A noção de grilagem verde está, portanto, associada diretamente a problemáticas relacionadas à criação de mecanismos que seriam ambientalmente mais sustentáveis, incluindo a criação de reservas florestais via a compra de créditos de carbono [...], acordos de Redução de Emissões por Diminuição do Desmatamento (REDD+), investimentos para a produção de energia limpa [...] entre outros mecanismos verdes. Em outros termos, apropriação verde vem sendo usada para caracterizar casos de apropriação de territórios em que as '[...] agendas ambientais [são] a motivação fundamental'[...], especialmente relacionada com as narrativas de mudanças do clima ou crise climática $[\ldots]^{51}$.
\end{abstract}

Sobre a ascensão da neoliberalização da natureza e suas faces ligadas ao green grabbing e land grabbing Fletcher, Dressler e Büscher (2014) escrevem

[...] these days it seems that the prime objective of conservation policy is to "grab green" locally, what Fairhead, Leach, and Scoones $(2012 b, 237)$ define as "the appropriation of land and resources for environmental ends." Hence, neoliberal conservation has become part of a discursive process manifesting materially as broader resource and landgrabs (White et al. 2012; Fairhead, Leach, and Scoones $2012 b$ ), the main goal of which is the appropriation of value of seemingly anything material and important as basic "inputs" for life. (FLETCHER, DRESSLER, BÜSCHER, 2014, p. 15).

No Brasil, associa-se as práticas e dispositivos de neoliberalização da natureza a publicação, em 28 de dezembro de 2018, do decreto federal 9.640, que regulamenta a Cota de Reserva Legal - CRA, instituída pelo artigo 44 da lei federal 12.651/12. A CRA é um dos mecanismos de compensação de déficit de Reserva Legal em imóveis rurais previstos no novo Código Florestal, um título verde, que representa a metamorfose da natureza em ativo financeiro ou nos chamados ativos ambientais ligados aos ditos serviços ambientais/ecossistêmicos. Para a Federação Brasileira de Bancos FEBRABAN (2015) as CRAs representam uma importante oportunidade de atrair capital privado, em larga escala, para o agronegócio e para a agenda florestal e de serviços ecossistêmicos brasileiros. Esses instrumentos são utilizados para a capitalização, "precificação" e "assetização" (BIRCH, 2016; 2017) das terras e natureza com segurança e transparência para os investidores, algo necessário dentro dos padrões neoliberais de governança corporativa do mercado global.

Sobre a massiva expropriação de bens comuns, ligada as ações de land/green grabbing tem-se que a mesma se apresenta como mais uma grande rodada de acumulação primitiva, só que agora vinculada aos agentes do capital financeiro, esses procuram transformar todas as formas de bens comuns (sociais, espaciais, civis, culturais, intelectuais [educativos] ${ }^{52}$ ) em mercadoria. Assim, todos eles se veem ameaçados a serem convertidos em bens rentistas. Para Standing (2017) esses bens são mais fundamentais para os membros do "precariado" do que para os agentes rentistaspatrimoniais, e é fundamental para a classe trabalhadora a limitação da transferência de bens/ativos públicos e/ou comuns para empresas a preços de saldo (STANDING, 2017).

\footnotetext{
51 Destaca-se aqui o processo de grilagem verde no cerrado brasileiro mostrado na reportagem "Cerrado: Traditional communities accuse agribusiness of 'green land grabbing"': "[...] chamamos de 'grilagem verde", explica Rigonato: A lei de proteção indígena no Brasil - o Novo Código Florestal legislado em $2012 \mathrm{com}$ a ajuda da poderosa bancada ruralista, o lobby do agronegócio - exige proprietários privados para proteger uma parte de sua vegetação nativa conhecida como Reserva Legal. Dependendo do bioma, uma Reserva Legal deve representar de 20 a 35\% da propriedade de um proprietário no Cerrado e até $80 \%$ na Amazônia. No entanto, o código não exige que essas terras protegidas sejam contíguas a áreas agrícolas desenvolvidas. Portanto, fazendas em grande escala têm reivindicado cada vez mais terras naturais - muitas vezes mantidas sem escritura por comunidades tradicionais - com o agronegócio contando-as como suas reservas". Disponível em: https://www.farmlandgrab.org/post/view/27990-cerrado-traditional-communities-accuse-agribusiness-of-green-land-grabbing. Acesso: 22 ago. 2020.

52 Sobre os bens comuns ligados ao conhecimento ver o livro: "Los bienes comunes del conocimiento", organizado por Charlotte Hess e Elinor Ostrom (2016).
} 
Destaca-se que, globalmente, os comuns estão sendo ameaçados, apropriados privativamente e destruídos, algo que demonstra muito bem a atual "fome do capital". Dessa forma tem-se a crescente privatização de recursos naturais, como o caso da água (water grabbing) ${ }^{53}$. Esse processo de privatização permite a seus novos detentores restrição de sua oferta (escassez artificial), desvio das mesmas para locais onde os ganhos com seu uso são maiores e garantidos- a exemplo dos projetos de integração de bacias, como a do rio São Francisco, além de aumento do seu preço. Sobre o processo de busca de apropriação e privatização dos bens comuns é na Inglaterra que é dado um passo decisivo nesse sentido, em 2012, o governo "Del Novo Laborismo" (STANDING, 2017) contratou uma companhia de pesquisa comercial para calcular o preço anual do ecossistema da Inglaterra, ao fim dos estudos, a empresa concluiu que parte do ecossistema possuiu um valor infinito ${ }^{54}$, ou seja nem todos os valores de uso da natureza são intercambiáveis em valores de troca. (HARVEY, 2011; 2014) $)^{55}$.

Contudo, isso não parou a sanha do governo inglês de mercantilizar e commodificar a natureza, o mesmo criou um "Grupo Especial de Trabajo sobre Mercados del Ecosistema" 56, esse novo estudo publicou um informe, em 2013, que afirmava haver identificado um considerável crescimento potencial dos mercados relacionados com a natureza (bens naturais) da ordem de milhares de milhões de libras ao ano (STANDING, 2017). Desse modo dar-se a proliferação de ideias ligadas a valorização da natureza por meio de conceitos como: capital natural, serviços ambientais/ecossistêmicos, energias renováveis e infraestrutura verde.

Trata-se da criação de métricas e medidas de custo-benefício (AALBERS, 2015; BIRCH, 2016) da natureza, assim como formas de avaliação monetária dos chamados serviços ecossistêmicos e ambientais, que passa a ser exigida por muitos governos e agências internacionais/organismos multilaterais como uma condição necessária para a preservação do chamado capital natural, ou até como contrapartidas de empréstimos. Podemos encontrar várias iniciativas e forças tarefas organizadas por instituições multilaterais, think thanks. Como exemplo temos as ações da World Business Council for Sustainable Development (WBCSD) ${ }^{57}$.

O chamado capital natural refere-se aos componentes bióticos e abióticos dos ecossistemas, diferentes das pessoas e do que é produzido pela sociedade. Esses contribuem para geração de bens e serviços com valor para as pessoas. Mas, a natureza não é capital, e chamá-la de "capital

\footnotetext{
53 Sobre o processo de "water grabbing" ver: "The Global Water Grab" (Hands Off the Land Alliance, 2014). Para mais informações sobre o processo de mercantilização e privatização da água na América Latina ver o livro "Água e Democracia na América Latina" (CASTRO [Org.], 2016). Disponível em: http://books.scielo.org/id/tn4y9/epub/castro-9788578794866.epub. Acesso: 20 maio 2020.

${ }^{54}$ Ver a reportagem do The Guardián; "Putting a price on the rivers and rain diminishes us all". Disponível em: https://www.theguardian.com/commentisfree/2012/aug/06/price-rivers-rain-greatest-privatisation. Acesso: 02 ago. 2020.

${ }_{55}$ Sobre o assunto ver BÜSCHER (et al, 2012) "Towards a Synthesized Critique of Neoliberal Conservation". In: Capitalism Nature Socialism. Disponível em: https://www.researchgate.net/publication/233029281_Towards_a_Synthesized_Critique_of_Neoliberal_Conservation. Acesso: 18 maio 2020.

${ }^{56}$ Sobre a emergência dessas narrativas e suas intenções de comercializar, "assetizar" e "commodificar" os bens comuns, e de ações como a do "Grupo Especial de Trabajo sobre Mercados del Ecosistema" citado, Standing assinala: "Los términos empleados por el Grupo Especial de Trabajo indican la intención de comercializar los bienes comunes. Su informe habla de "capital natural", "servicios del ecossistema", "infraestructura verde" y "clases de activos" (también conocidos por hábitats), todo ello en el seno de un "mercado de ecossistemas". Al responder a sus recomendaciones, el gobierno se refirió a los terratenientes como "provedores de servicios del ecossistema", que presumiblemente podrían esperar ser pagados o subvencionados por proveer los "servicios" en cuestión. Entretanto, el Grupo Especial de Trabajo recomendaba acudir a los rentistas finales, hablando de "aprovechar la experiência financiera de la City para valorar las formas de que esa combinación de fuentes de ingressos y titulizaciones potencie el retorno sobre la inversión de un bono medioambiental"”. (STANDING, 2017, p.180).

${ }^{57}$ Segundo seu site a WBCSD é uma organização global liderada por CEOs de mais de 200 empresas líderes que trabalham juntas para acelerar a transição para um mundo sustentável. As empresas membro são provenientes de todos os setores de negócios e de todas as principais economias, representando uma receita combinada de mais de US $\$ 8,5$ trilhões. A organização possui alguns projetos setoriais como: Grupo de Soluções Florestais (FSG) - que busca formas de fornecer, continuamente, materiais renováveis para a bioeconomia e ações ligadas ao sequestro de carbono, água potável, habitat, meios de subsistência econômicos; e executar a Bioeconomia Sustentável, responsável pela transição para uma economia circular e de baixo carbono. Global Agribusiness Alliance (GAA) - é a primeira aliança global de sustentabilidade do gênero com empresas do setor privado em toda a cadeia de valor de alimentos e não-alimentos. Os membros estão espalhados pelo mundo, são produtores, comerciantes, fabricantes de fertilizantes e agroquímicos, fornecedores de sementes, processadores primários e fornecedores de agrotecnologia de culturas alimentícias e não alimentícias. Disponível em: https://www.wbcsd.org/.
} Acesso: 25 abr. 2020. 
natural" leva ao abandono da ideia e concepção de bem comum (STANDING, 2017). Cabe ressaltar que a reflexão sobre os comuns vem se dando, na maioria das vezes, polarizada entre a intervenção estatal autoritária e as soluções que derivam dos direitos sobre a propriedade privada. Nesse contexto a propriedade direta da terra realizada coletivamente, na forma de seu valor de uso, ou de espaços comuns e/ou comuns espaciais (STANDING, 2017), praticamente, está desaparecendo, à medida que o modelo hegemônico de propriedade, que geralmente se dá sob três formas: individual/familiar; empresarial, e estatal/institucional tem sido aceito sem questionamentos. O modelo de propriedade hegemônico e sua maior concentração via dispositivos neoliberais conduz e sustenta a produção e reprodução de profunda injustiças socioespaciais. Essas injustiças socioespaciais estão gravadas na chamada paisagem geográfica de acumulação do capital (HARVEY, 2011), que está em perpétua evolução, com destaque para o impulso das necessidades especulativas de acumulação adicional - que inclui a especulação sobre a terra e os bens comuns - e, só secundariamente se preocupa com as necessidades das pessoas.

\section{CONSIDERAÇÕES FINAIS}

Tais processos e fenômenos relatados, como se expôs, não se dão sem contradições, esses convivem com a expulsão e despossessão de populações inteiras, essas têm sido expulsas de seus territórios, ou tendo seus bens comuns expropriados e mercantilizados. Sobre isso a socióloga Saskia Sassen (2016) escreve seu livro "Expulsões: brutalidade e complexidade na economia global" onde aponta que emerge uma maciça perda de habitat no hemisfério sul devido à expansão da mineração, do agronegócio, da disputa por água, da expansão das cidades. Soma-se a isso o crescimento do mercado de carbono que tem convertido campos e florestas em ativos e/ou sumidouros de carbono para que empresas poluidoras possam comprar tais ativos para compensar suas emissões nocivas ${ }^{58}$. (BÖHM; MISOCZKY; MOOG, 2012).

Observou-se, também, a tentativa de produção de um consenso global quanto a importância dessa exploração para os países explorados, que se dá em paralelo com a emergência de lutas de resistência em um ambiente político cada vez mais pós-democrático, este está ligado ao processo de maior exploração do capital, no período neoliberal, onde tem-se a emergência da governança corporativa transmutada das empresas para a ação estatal que levam a uma competição sem freios, entre empresas, indivíduos, territórios, governos. Tal competição tem gerado um concentração e centralização sem precedentes de capital nas mãos de corporações que tem inflado seu tamanho e poder, essas passam a expandir suas ações e atividades de forma cada vez mais global e a procurar metamorfosear toda sorte de bens e serviços em mercadorias, incluindo-se os tradicionais bens comuns.

Sobre essa crescente competição utiliza-se a relação feita por Swyngedouw (2005) entre a política da governança, como uma inovação social, ou um dispositivo neoliberal de controle e comando, que se realiza via toda sorte de arranjos políticos-institucionais, econômicos e espaciais defendidos por OMLs (OCDE, Banco Mundial, ONU etc.) e corporações, esses dispositivos - as chamada boas práticas - são apontados como o único caminho para uma maior inclusão social, redução da pobreza e fome, redução dos efeitos do aquecimento global. Estes veem sendo aplicados em uma variedade territórios e escalas geográficas sem mediações quanto sua adaptabilidade a diferentes formações sócio-territoriais.

Tudo isso, caminha na direção da erosão da possibilidade de construção de uma democracia substantiva ${ }^{59}$ e de um mundo menos desigual, pois de maneira contraditória essas novas agendas de governança global criam dispositivos de apropriação, controle e "precificação" dos bens comuns e, ao

58 Segundo artigo do Grupo ETC - grupo de ação global que trabalha para resolver as questões socioeconômicas e ecológicas que envolvem as novas tecnologias, que podem ter um impacto nas pessoas mais pobres e vulneráveis do mundo o comércio de carbono falhou totalmente em abordar as verdadeiras causas da crise climática. Nunca foi feito para fazê-lo. Em vez de reduzir as emissões de carbono em sua fonte, criou um mercado lucrativo para poluidores e especuladores comprarem e venderem créditos de carbono enquanto continuam a poluir. Agora, a pressão está aumentando para tratar as terras agrícolas como um grande sumidouro de carbono, que pode ser reivindicado como mais um contrapeso às emissões industriais. Os governos dos EUA e da Austrália, o Banco Mundial e o setor corporativo há muito tempo defendem isso e a criação de novos mercados de carbono onde eles possam comprar compensações terrestres nos países em desenvolvimento. Disponível em: http://www.etcgroup.org/content/climate-summit-dont-turn-farmers-climate-smart-carbon-traders. Acesso: 21 maio 2020.

59 "Mészáros: Igualdade substantiva e democracia substantiva". Disponível https://www.cartamaior.com.br/?/Editoria/Arte/Meszaros-Igualdade-substantiva-e-democracia-substantiva/39/39030. Acesso: 23 jul. 2020. 
mesmo tempo, capacitam novos atores/players, enquanto desapoderam e aniquilam outros - através, inclusive, do que Mbembe (2016) vem chamando de necropolítica. Argumenta-se que essa mudança de "governo" para "governança" está associada à consolidação de novas tecnologias de governo neoliberais, por um lado, e com a profunda reestruturação dos parâmetros da democracia política, por outro, levando a um déficit democrático substancial (SWYNGEDOUW, 2005). Esse padrão de governança associa-se ao que Lazzarato (2015) denomina "tecnologias de poder del capitalismo neoliberal" ou aos dispositivos de Agamben (2005).

$\mathrm{Na}$ tentativa de ligar o fenômeno da pós-democracia com o paradigma das mudanças climáticas Swyngedouw (2010), no artigo "Apocalypse Forever? Post-political Populism and the Spectre of Climate Change", aponta que vivemos, atualmente, uma relação aparentemente paradoxal, a relação entre dois temas aparentemente desconexos: a apresentação e formação de um consenso global em torno do problema das mudanças climáticas, por um lado, e do debate político que gira em torno do surgimento e consolidação de uma condição pós-política e pós-democrática.

Conclui-se, que o paradigma das mudanças climáticas é uma das arenas na qual um quadro pós-político e a configuração política pós-democrática está sendo mediada, e tem propiciado uma corrida global por terras e certo rentismo ecológico manifestado nas análises dos fenômenos de land grabbing e green grabbing, que por sua vez estão associados a práticas neoliberalizantes e financeiras presentes na construção de certa agenda global construída sobre o discurso apocalíptico de uma sociedade de risco global, essa vem sendo construída via tecnologias socias de poder presentes nos processos de neoliberalização e financeirização.

\section{REFERÊNCIAS}

ACSERALD, H; CAMPELLO, C. A.; BEZERRA, G. N. O que é justiça ambiental. Rio de Janeiro: Garamond, 2009.

AGAMBEN, G. O que é um dispositivo? Outra Travessia. Santa Catarina, 2005.

APOSTOLOPOULOU, E.; ADAMS, W. M. Biodiversity offsetting and conservation: reframing nature to save it. Oryx, v. 51, n. 1, 2015, pp. 23-31. https://doi.org/10.1017/S0030605315000782

ASOCIACIÓN LATINOAMERICANA DE INSTITUCIONES FINANCIERAS PARA EL DESARROLLO ALIDE. Mercado de Bonos Verdes: ¿quiénes son sus protagonistas?". G20/ALIDE, 2019.

BECK, Ulrich. World at risk. Cambridge: Polity Press, 2009.

. Las metamorfoses del mundo. Barcelona: Paidós-Espasa Libros, 2017.

BERNARDO, Carolina Tavares da Silva; NOGUEIRA, Jorge Madeira. Os 15 anos de SNUC: uma análise à luz da Economia Ambiental. Espacios. Vol. 37, N. 21, 2016.

$\mathrm{BIRCH}, \mathrm{K}$. The Neoliberal Underpinnings of the Bioeconomy: the Ideological Discourses and Practices of Economic Competitiveness. Genomics, Society and Policy, 2(3). 2006. Disponível em: https://scihub.tw/10.1186/1746-5354-2-3-1. Acesso: 23 mar. 2020. https://doi.org/10.1186/1746-5354-2-3-1

Rethinking Value in the Bio-economy: Finance, Assetization, and the Management of Value. Sci Technol Human Values. May, V. 42, N.3, 2017, 460-490. Disponível em: https://journals.sagepub.com/doi/10.1177/0162243916661633. Acesso: 25 mar. 2020 . https://doi.org/10.1177/0162243916661633

BÖHM, S; MIZOCZKY, M. C.; MOOG, S. Greening Capitalism? A Marxist Critique of Carbon Markets. Organization Studies, 2012. Disponível em: https://core.ac.uk/download/pdf/16387374.pdf. Acesso: 20 set. 2020.

BORRAS JR., S.; SAUER, S. 'LAND GRABBING' E 'GREEN GRABBING': Uma leitura da 'corrida na produção acadêmica' sobre a apropriação global de terras. Campo-Território. Ed. Especial, pp. 6-42, 2016.

BRANDÃO, Carlos. Acumulação primitiva permanente e desenvolvimento capitalista no Brasil contemporâneo. In: ALMEIDA, Alfredo W. B. (et al.). Capitalismo globalizado e recursos territoriais. Rio de Janeiro: Lamparina, 2010. 
Crise e rodadas de neoliberalização: impactos nos espaços metropolitanos e no mundo do trabalho no Brasil. Cad. Metrop., v. 19, n. 38, pp. 45-69, jan/abr 2017. https://doi.org/10.1590/22369996.2017-3802

BRENNER, N. A globalização como reterritorialização: o reescalonamento da governança urbana na União Europeia. Cadernos Metrópole, 12, 24, pp. 535-564, 2010.

BRENNER, Neil; PECK, Jamie; THEODORE, Nik. Mal-estar no Pós-Neoliberalismo. Dossiê Crise Global. Novos Estudos, n. 92, 2012.

CHESNAIS, F. A Mundialização do Capital. Tradução: Silvana Finzi Foá, São Paulo: Xamã, 1996.

. O Capital portador de juros: acumulação, internacionalização, efeitos econômicos e políticos. In: CHESNAIS, F. (org.). A finança mundializada. São Paulo: Boitempo. 2005. p. 35 -67.

COLLARD, Rosemary-Claire; DEMPSEY, Jessica. Life for sale? The politics of lively commodities. Environment and Planning. V. 45, 2013, pp. 2682-2699. https://doi.org/10.1068/a45692

DEMPSEY, Jessica; ROBERTSON, Morgan M. Ecosystem services: Tensions, impurities, and points of engagement within neoliberalismo. Progress in Human Geography. v. 36, n. 6, 2012, pp. 758-779. https://doi.org/10.1177/0309132512437076

DEMPSEY, Jessica. Enterprising Nature - Economics, Markets and Finance in Global Biodiversity Politics. Chichester: John Wiley \& Sons, 2016, 311pp. https://doi.org/10.1002/9781118640517

DOWBOR, Ladislau. A era do capital improdutivo: por que oito famílias têm mais riqueza do que a metade da população do mundo? São Paulo: Autonomia Literária, 2017.

ETC Group. La alimentación mundial: entre inversiones oscuras y datos massivos. Cuaderno \#116, Set. 2018. Disponível em: http://www.etcgroup.org/sites/www.etcgroup.org/files/files/bbrhp__spanish_v2_oct_5.pdf. Acesso: 01 abr. 2020.

. Tecno-fusiones comestibles - Mapa del poder corporativo en la cadena alimentaria. Ciudad del México: Group ETC, 2019.

ETC Group; MOONEY, Pat. La insostenible Agricultura 4.0 - Digitalización y poder corporativo en la cadena alimentaria. Ciudad del México: Group ETC, 2019.

FAIRHEAD, J., M. LEACH, AND I. SCOONES. Green Grabbing: A New Appropriation of Nature? Journal of Peasant Studies. V. 39, n. 2, pp: 237-61, 2012. https://doi.org/10.1080/03066150.2012.671770

FERNANDES, Bernardo M. Transformações no Brasil agrário nas fases neoliberais e pós-neoliberal: construindo uma política agrária para o desenvolvimento sustentável. In: SURTEGARAY, D. (et al). Geografia e conjuntura brasileira. Rio de Janeiro: Consequência, 2017.

FERNANDES, Bernardo M.; FREDERICO, Samuel; PEREIRA, Lorena I. Acumulação pela renda da terra e disputas territoriais na fronteira agrícola brasileira. Rev. NERA, v. 22, n. 47, pp. 173-201, 2019.

FOSTER, Jonh Bellamy; CLARK, Brett. Imperialismo ecológico: a maldição do capitalismo. Socialist Register 2004, 2006.

FOUCAULT, Michel. Sociedade, Território, População. São Paulo: Martins Fontes, 2008.

FREDERICO, Samuel; ALMEIDA, Marina C. de. Capital financeiro, land grabbing e a multiescalaridade na grilagem de terra na região do MATOPIBA. Rev. NERA, v. 22, n. 47, pp. 123-147, 2019.

FURTADO, Fabrina Pontes. Em Nome do Clima: - instituições e práticas na ambientalização das finanças no Brasil. Tese (Doutorado Planejamento Urbano e Regional) - Instituto de Pesquisa e Planejamento Urbano e Regional - IPPUR/UFRJ. Rio de Janeiro, 2015.

GRÜN, Roberto. Convergência das elites e inovações financeiras: a governança corporativa no Brasil. RBCS, Vol. 20, n. 58 jun., 2005. https://doi.org/10.1590/S0102-69092005000200004

HARVEY, David. Justice, Nature \& the Geography of Difference. Oxford: Blackwell Publishers, 1996.

. O enigma do capital: e as crises do capitalismo. São Paulo: Boitempo, 2011.

. Seventeen Contradictions and the End of Capitalism. New York: Oxford University Press, 2014. 
IPES-FOOD; ETC GROUP. Demasiado grandes para alimentarnos. 2017.

KLEIN, Naomi. A doutrina do choque: a ascensão do capitalismo de desastre. Rio de Janeiro: Nova Fronteira, 2008.

LAZZARATO, Mauricio. Gobernar a través de la deuda: tecnologias de poder del capitalismo neoliberal. Buenos Aires/Madrid: Amorrortu Editores, 2015.

MÉSZÁROS, István. Para além do capital: rumo a uma teoria da transição. 1.ed. revista. - São Paulo: Boitempo, 2011.

MINITÉRIO PÚBLICO FEDERAL - PROCURADORIA FEDERAL DOS DIREITOS DO CIDADÃO. Nota Técnica n 1/2020/PFDC/MPF, de 3 de fevereiro de 2020. Brasília: MPF/PFDC, 2020.

MOYO, Dambysa. El ganhador se queda com lucro: la fiebre china por el control de los recursos naturales y lo que supone para el mundo. Tradución de Casandra Viñuela. Barcelona: Galaxia Gutenberg, 2013.

MUNIZ, Rodrigo. Permissão para degradar: uma análise crítica dos biodiversity offsets nas práticas conservacionistas. Kairos. Journal of Philosophy \& Science.N. 21, 2019. https://doi.org/10.2478/kjps$\underline{2019-0003}$

NATURAL RESOURCE GOVERNANCE INSTITUTE. Índice de la Gobernanza de los Recursos Naturales - 2017. Disponível em: www.resourcegovernanceindex.org. 2017.

OLIVEIRA, Francisco. A dominação globalizada: estrutura e dinâmica da dominação burguesa no Brasil. En publicación: Neoliberalismo y sectores dominantes. Tendencias globales y experiencias nacionales. BASUALDO, Eduardo M.; ARCEO, Enrique. Buenos Aires: CLACSO, Consejo Latinoamericano de Ciencias Sociales, Agosto, 2006.

OCDE. "The business case for biodiversity action", In: Biodiversity: Finance and the Economic and Business Case for Action, OCDE Publishing, Paris, https://doi.org/10.1787/35195c41-en

ONU - ORGANIZAÇÃO DAS NAÇÕES UNIDAS. Objetivos do Desenvolvimento Sustentável. Disponível em: https://nacoesunidas.org/pos2015/. Acesso: 23 jul. 2020.

PACKER, L. A. Novo código florestal \& pagamentos por serviços ambientais: regime proprietário sobre os bens comuns. Curitiba: Juruá, 2015.

PAULANI, Leda. Brasil Delivery: servidão financeira e estado de emergência econômico. São Paulo: Boitempo, 2008.

PEREIRA, Lorena Izá. Liberação na aquisição de imóveis rurais por estrangeiros no Brasil e o controle de terras. Boletim DATALUTA, n. 112, Artigo do mês: abril de 2017.

PORTO-GONÇALVES, Carlo W. Geo-grafías: movimentos sociales, nuevas territorialidades y sustentabilidade. Siglo Veintiuno Editores, 2003.

REYDON, B. P., FERNANDES, V. B., BUENO, A. P. S. (Orgs.). II Seminário Governança de Terras e Desenvolvimento Econômico. Campinas: Unicamp/IE, 2016. Disponível em: http://governancadeterras.com.br/wp-content/ uploads/2017/01/Coleta\%CC\%82nea-IISemina\%CC\%81rio.pdf. https://doi.org/10.1590/1982-3533.2017v26n4art12

REYDON, B. P. FERNANDES, V. B. Financialization, land prices and land grab: a study based on the Brazilian reality. Economia e Sociedade, v. 26, Número Especial, p. 1149-1179, dez. 2017.

SANTOS, Boaventura de Sousa. Refundación del Estado en América Latina: Perspectivas desde una epistemología del Sur. Lima: Instituto Internacional de Derecho y Sociedad, 2010.

SANTOS, M. A natureza do espaço: técnica, tempo, razão e emoção. São Paulo: Hucitec, 2002.

. Economia espacial: críticas e alternativas. São Paulo: HUCITEC, 2007 [1979].

SASSEN, Saskia. Expulsões: brutalidade e complexidade na economia global. Rio de Janeiro: Paz \& Terra, 2016.

SEUFERT, P.; MENDONÇA, M. L.; PITTA, F. When Land Becomes a Global Financial Asset The MATOPIBA Case in Brazil. 2018. Disponivel em: https://www.righttofoodandnutrition.org/when-landbecomes-global-financial-asset. Acesso: 23 jul. 2020. 
SILVEIRA, Gilberto Borges; MUNIZ, Sérgio Tadeu Gonçalves. Pagamento por serviços ambientais: o caso da compensação de reserva legal. REA - Revista de estudos ambientais (Online) v.16, n. 1, p. 16-26, jan.jun. 2014.

STIGLITZ. Joseph (et al). A economia mais forte do mundo: um plano para revitalizar a economia americana e promover a prosperidade global. Lisboa: Bertrand, 2017.

SULLIVAN, Sian. Banking Nature? The Spectacular Financialisation of Environmental Conservation. Antipode. v. 45, n. 01, 2013, pp. 198-217. https://doi.org/10.1111/j.1467-8330.2012.00989.x

WRI - WORLD RESOURCES INSTITUTE. World resources 2002-2004 - decisions for the Earth: balance, voice, and power. Washington: WRI, 2003.

WARD, Callum; SWYNGEDOUW, Erik. Neoliberalisation from the Ground Up: Insurgent Capital, Regional Struggle, and the Assetisation of Land. Antipode, v. 0, n. 0, pp. 1-21, 2018.

Recebido em: 20/09/2020

Aceito para publicação em: 22/11/2020 